University of Nebraska - Lincoln

DigitalCommons@University of Nebraska - Lincoln

\title{
$9-2013$
}

\section{Managing Capital Market and Longevity Risks in a Defined Benefit Pension Plan}

Samuel H. Cox

University of Manitoba, sam.cox@ad.umanitoba.ca

Yijia Lin

University of Nebraska-Lincoln, yijialin@unl.edu

Ruilin Tian

North Dakota State University, ruilin.tian@ndsu.edu

Jifeng Yu

University of Nebraska-Lincoln, jifeng.yu@unl.edu

Follow this and additional works at: https://digitalcommons.unl.edu/managementfacpub

Cox, Samuel H.; Lin, Yijia; Tian, Ruilin; and Yu, Jifeng, "Managing Capital Market and Longevity Risks in a Defined Benefit Pension Plan" (2013). Management Department Faculty Publications. 104.

https://digitalcommons.unl.edu/managementfacpub/104

This Article is brought to you for free and open access by the Management Department at DigitalCommons@University of Nebraska - Lincoln. It has been accepted for inclusion in Management Department Faculty Publications by an authorized administrator of DigitalCommons@University of Nebraska - Lincoln. 
Published in Journal of Risk and Insurance 80:3 (September 2013), pages 585-619;

doi: 10.1111/j.1539-6975.2012.01508.x

Copyright $\odot 2013$ The Journal of Risk and Insurance.

Published by John Wiley \& Sons, Inc. Used by permission.

Published online April 10, 2013.

\title{
Managing Capital Market and Longevity Risks in a Defined Benefit Pension Plan
}

\author{
Samuel H. Cox, Yijia Lin, Ruilin Tian, and Jifeng Yu
}

\begin{abstract}
This article proposes a model for a defined benefit pension plan to minimize total funding variation while controlling expected total pension cost and funding downside risk throughout the life of a pension cohort. With this setup, we first investigate the plan's optimal contribution and asset allocation strategies, given the projection of stochastic asset returns and random mortality evolutions. To manage longevity risk, the plan can use either the ground-up hedging strategy or the excess-risk hedging strategy. Our numerical examples demonstrate that the plan transfers more unexpected longevity risk with the excess-risk strategy due to its lower total hedge cost and more attractive structure.
\end{abstract}

\section{Introduction}

Operating defined benefit (DB) pension plans involves risks: no matter what happens in financial markets and how long employees live after retirement, DB plans are responsible for providing employees guaranteed retirement income. The inherent volatility of the capital market and longevity risk force the sponsors of the DB pension plans to manage pension risk.

The DB pension plans can reduce risk by pursuing a strategy with stable contributions (Lee, 1986). In this light, Haberman, Butt, and Megaloudi (2000) investigate an optimization

Samuel H. Cox is the L. A. H. Warren Chair Professor at the Asper School of Business, University of Manitoba. Yijia Lin is in the Department of Finance, College of Business Administration, University of Nebraska-Lincoln. Ruilin Tian is in the Department of Accounting, Finance, and Information System, College of Business, North Dakota State University. Jifeng Yu is in the Department of Management, College of Business Administration, University of Nebraska-Lincoln. The second author can be contacted via e-mail: yijialin@unl.edu. This article was presented at the seventh International Longevity Risk and Capital Market Solutions Symposium in Frankfurt, Germany, in September 2011. The authors appreciate helpful comments from the participants at the meeting. The authors also thank the associate editor and the two anonymous referees for their very helpful suggestions and comments during the revision process. 
problem with an objective to minimize the variance of periodic contributions. To cope with the risk, the sponsors can also adjust their asset allocation (Black, 1989; Bodie, 1991; Haberman, Butt, and Megaloudi, 2000; Colombo and Haberman, 2005; Maurer, Mitchell, and Rogalla, 2009; Lucas and Zeldes, 2009). A group of researchers is in favor of holding a 100 percent bond portfolio to minimize pension risk (Black, 1980; Gold and Hudson, 2003). The most prominent example of a company that follows this advice is the Boots, a U.K. pharmaceutical retailer, which shifted all of its pension assets to bonds between the spring of 2000 and July 2001.1 Yet, given that there exists a trade-off between contribution and the level of risk a DB scheme is willing to take (Colombo and Haberman, 2005), this practice may raise total pension cost as more contributions are needed to meet retirement benefit liabilities. Total pension cost includes all costs and penalties associated with normal contributions, supplementary contributions, and withdrawals (Maurer, Mitchell, and Rogalla, 2009). By contrast, some others advocate investing heavily in higher yielding but riskier equities, reasoning that stocks are expected to earn higher returns than bonds over the long haul and help to reduce underfunding over time. Still, there is a problem of this strategy. That is, equity investment increases funding variation and leads to a high funding downside risk, that is, the risk that pension assets fall far below pension liabilities. Thus, pension investment strategy should take into account both funding downside risk and total pension cost.

To derive the optimal proportion invested in risky assets, Maurer, Mitchell, and Rogalla (2009) minimize the variance of plan contributions subject to a total pension cost constraint but they do not explicitly control the plan's funding downside risk. Delong, Gerrard, and Haberman (2008), on the other hand, investigate the optimal investment strategy by minimizing funding variation. While they include supplementary contributions in their generalized optimization problem, they do not directly study the effect of total pension cost on pension asset allocation. Josa-Fombellida and RincÓn-Zapatero (2004) also examine the pension asset allocation with the aim of minimizing pension funding risk and contribution rate risk, along the lines of Haberman and Sung (1994), Haberman (1997), and Josa-Fombellida and RincÓn-Zapatero (2001). They conclude that the plan will invest more in risky assets (e.g., stocks) when the funding status deteriorates. Bogentoft, Romeijn, and Uryasev (2001) model a multi-period problem to adjust contributions and investments at each decision point by minimizing pension cost subject to a conditional value at risk $(\mathrm{CVaR})$ constraint on pension underfunding. Based on a pension fund data from the Netherlands, they suggest investing, on average, 84 percent of the pension fund in bonds and the remainder in equities. Similar to Delong, Gerrard, and Haberman (2008), Josa-Fombellida and RincÓn-Zapatero (2004) and Bogentoft, Romeijn, and Uryasev (2001) do not directly control total pension cost at a given level. Nevertheless, considering a total pension cost constraint is important since it includes all costs a plan incurs during a period of interest. The budget constraint creates a strong incentive for the plan to specify a target total pension cost.

To extend the previous analysis, in an asset-liability management setting with various stochastic assets and dynamic mortality rates, not only do we propose a problem to

1. However, the plan partially shifted back to equity investment in 2005. 
minimize funding variation of a DB pension plan, but we also impose a constraint to specify expected total pension cost and a $\mathrm{CVaR}$ constraint to control downside risk from pension underfunding. We consider a financial market with a low-risk asset driven by a Brownian motion and each risky asset driven by a Lévy process. The dynamic mortality rates are described by the Lee and Carter (1992) model. Our model is straightforward and easy to implement.

Longevity risk has been recognized as a major threat to pension sponsors. Delong, Gerrard, and Haberman (2008) conclude that pension plans with higher longevity risk are subject to higher costs. We analyze how the optimal normal contribution and asset allocation will change with different levels of mortality improvement. Our numerical results show that given a funding downside risk tolerance, a higher life expectancy of pensioners leads to a higher optimal normal contribution and a higher percentage of funds invested in lowrisk assets. In our example, when the common risk parameter in the Lee and Carter (1992) model decreases from -0.40 to $x_{0}$ (a more negative common risk parameter implies a higher level of mortality improvement), the expected total pension cost rises by 33 percent.

To ensure the long-term financial health of pension plans, sponsors must find ways to mitigate longevity risk. The topic of longevity risk management of pension plans has attracted a great deal of attention in academics and industries (Lin and Cox, 2005, 2008; Blake et al., 2006; Cairns, Blake, and Dowd, 2006; Cox and Lin, 2007; Sherris and Wills, 2008; Brcic and Brisebois, 2010; Wills and Sherris, 2010). These authors discuss possible longevity risk management solutions such as plan design, annuity purchase, and longevity securities. We take this discussion one step further. Instead of just comparing and proposing different longevity hedging tools, we study how much longevity risk a plan should transfer. In particular, we add a longevity hedging element to our pension optimization problem. Given this setup, we solve for the plan's optimal hedge ratio.

Specifically, we look for optimal solutions for two longevity risk hedging strategies: the ground-up hedging strategy and the excess-risk hedging strategy. The ground-up hedging strategy transfers a proportion of all future retirement payments. A prominent example of the ground-up strategy is the EIB longevity bond offered in 2004. The excess-risk strategy is to cede the part of longevity risk that exceeds a given level. The 2008 survivor swap between Canada Life and owners of insurance-linked securities as well as other investors is based on this idea. Compared to the excess-risk hedging strategy, the ground-up strategy is more expensive and capital intensive. Our optimization results show that there exists a negative relation between hedge ratio and longevity hedge cost. Therefore, the plan tends to hedge much less with the ground-up hedging strategy. Our results offer a new explanation for the failure of the EIB bond. The approach is unique in that it describes how a longevity risk management strategy affects the magnitude of the plan's hedge costs, which in turn determines its hedge level, whereas the earlier research on pension assetliability optimization does not numerically analyze longevity risk transfer.

The article is organized as follows. The "Pension Fund Optimization" section describes the pension fund optimization model. We provide a numerical example to illustrate how to implement our model for a DB pension plan with a single cohort of employees. Then we 
illustrate how longevity risk changes the optimal normal contribution and asset allocation. To hedge longevity risk, we examine the ground-up longevity risk hedging strategy in the section "Managing Pension Longevity Risks With the Ground-Up Hedging Strategy" The excess-risk hedging strategy has a lower cost than the ground-up hedging strategy. The section "Managing Pension Longevity Risks With the Excess-Risk Hedging Strategy" shows that the plan tends to hedge more unexpected risk with the excess-risk strategy. The results from the above-mentioned two sections provide important insights for longevity securitization, which is discussed in the "Implications for Longevity Securitization" section. The last section concludes the article.

\section{Pension Fund Optimization}

\section{Basic Framework}

Here we analyze a cohort whose members join a DB plan at the age of $x_{0}$ at time 0 and retire at the age of $x$ at time T. We look for an optimal pension asset allocation and contribution strategy throughout the life of the cohort for the DB plan. In our setting, one period is a year. We further assume the cohort is stable across the entire accumulation phase. That is, every member who withdraws is replaced by a one at the same age.

In terms of the future curtate lifetime $K(x)$ at age $x$, the present value of benefits of 1 per year is an annuity for $K(x)$ years:

$$
a \overline{K(x)}= \begin{cases}v^{1}+v^{2}+\cdots+v^{K(x)} & \text { if } K(x) \geq 1 \\ 0 & \text { if } K(x)=0,\end{cases}
$$

where $v=1 /(1+r)$ is the discount factor at the discount rate $r$.

The probability that a plan member age $x$ at time $T$ survives to age $x+s$ at time $T+s$ (and gets a benefit payment) given the mortality table at time $T$ is denoted as ${ }_{s} \tilde{p}_{x, T}$. These are random variables for $s=1,2, \ldots$, which we will simulate later. Define the conditional expected s-year survival rate for age $x$ at retirement $T$ as

$$
{ }_{s} \hat{p}_{x, T}=\mathrm{E}\left[s \tilde{p}_{x, T} \mid \tilde{p}_{x, T}, \tilde{p}_{x+1, T+1}, \ldots, \tilde{p}_{x+s-1, T+s-1}\right] .
$$

This allows us to compute the conditional expected value of life annuity in (1) as

$$
a(x(T))=\sum_{s=1}^{\infty} v_{s}^{s} \hat{p}_{x, T}
$$

That is, the life annuity factor for age $x$ at retirement $T, a(x(T))$, is the discounted conditional expected value of payments of 1 per year as long as the retiree survives. This conditional expected value depends on future survival rates $\tilde{p}_{x, T}$, which are random variables viewed from time 0 because we are considering the mortality table to be random whereas in practice it is an estimate of future rates. 
We can similarly define the life annuity factor for a retiree age $y$. After retirement $T$, the life annuity factor for age $y(y>x)$ at time $t(t>T), a(y(T))$, is determined as:

$$
a(y(t))=\sum_{s=1}^{\infty} v_{s}^{s} \hat{p}_{y, t} \quad y=x+1, \ldots ; \quad t=T+1, \ldots
$$

Here ${ }_{s} \hat{p}_{y, t}$ is the conditional expected s-year survival rate for age $y$ at time $t$,

$$
s \hat{p}_{y, t}=\mathrm{E}\left[s \tilde{p}_{y, t} \mid \tilde{p}_{y, t}, \tilde{p}_{y+1, t+1}, \ldots, \tilde{p}_{y+s-1, t+s-1}\right]
$$

where $\tilde{p}_{y, t}$ is the probability that the retiree age $y$ at time $t$ survives to age $y+s$ (and gets a benefit payment).

Suppose the plan starts with an accumulated fund $P A_{0}=M$ at time 0 , which is invested in different assets. The value of the accumulated fund $P A_{t}$ at time $t$ depends on the amount invested in asset $i$ at time $t-1, A_{i, t-1}$, and its return in period $t, r_{i, t}$ :

$$
P A_{t}=\sum_{i=1}^{n} A_{i, t-1}\left(1+r_{i, t}\right) \quad i=1,2, \ldots, n ; \quad t=1,2, \ldots
$$

Regulations require the following balance equation to hold:

$$
\sum_{i=1}^{n} A_{i, t}= \begin{cases}P A_{t}+C+k \cdot U L_{t} & t=1,2, \ldots, T \\ P A_{t}+k \cdot U L_{t}-B \cdot t-T \hat{p}_{x, T} & t=T+1, T+2, \ldots\end{cases}
$$

where ${ }_{t-T} \hat{p}_{x, T}$ is the conditional expected probability that a plan member age $x$ at time $T$ survives $t-T$ years when $t>T$,

$$
{ }_{t-T} \hat{p}_{x, T}=\mathrm{E}\left[t-T \tilde{p}_{x, T} \mid \tilde{p}_{x, T}, \tilde{p}_{x+1, T+1}, \ldots, \tilde{p}_{x+t-T-1, t-1}\right]
$$

The normal contribution (or the normal cost) $C$ represents new benefits earned by active participants each year. Following Haberman, Butt, and Megaloudi (2000), Maurer, Mitchell, and Rogalla (2009), and others, we assume the plan is free to choose a fixed normal contribution to minimize the variability of annual contributions. This means during the accumulation phase $(t \leq T)$, the sum of all investments at $t, \sum_{i=1}^{n} A_{i, t}$, equals the accumulated fund $P A_{t}$ plus a constant normal contribution $C$ (to be determined by optimization in the later sections) and a supplementary contribution $k \cdot U L_{t^{\prime}}$ where $k$ is the pension amortization factor and $U L_{t}$ is the plan's unfunded liability at time $t$. After retirement $(t>T)$, the available fund for investment at time $t$ is reduced by the benefits paid to the survivors, $B \cdot_{t-T} \hat{p}_{x, T}$, where the constant $B$ is the promised annual survival payment after the plan participants reach retirement age $x$ at time $T$. It depends on the number of pensionable service years accrued until $T$ and projected salaries before retirement. 
We assume that regulations allow the plan to amortize the unfunded liability over $m>1$ periods at the plan's periodic discount rate $\rho$. This approach is common; see, for example, Maurer, Mitchell, and Rogalla (2009). ${ }^{2}$ Therefore, the pension amortization factor $k$ equals

$$
k=1 / \ddot{a} \bar{m} \mid \rho
$$

where

$$
\ddot{a}_{\bar{m} \mid \rho}=\sum_{i=0}^{m-1} \frac{1}{(1+\rho)^{i}}
$$

Following the literature, when $t \leq T$, the plan's unfunded liability $U L_{t}$ equals

$$
\begin{aligned}
U L_{t} & =P B O_{t}-P A_{t}-C \\
& =P B O_{t}-\sum_{i=1}^{n} A_{i, t}+k \cdot U L_{t} \quad t=1,2, \ldots, T
\end{aligned}
$$

When $t>T, U L_{t}$ equals

$$
\begin{aligned}
U L_{t} & =P B O_{t}-P A_{t}+B \cdot t-T \hat{p}_{x, T} \\
& =P B O_{t}-\sum_{i=1}^{n} A_{i, t}+k \cdot U L_{t} \quad t=T+1, T+2, \ldots
\end{aligned}
$$

In (7) and (8), the pension liability at time $t, P B O_{t^{\prime}}$ is defined as the discounted value of future benefit obligations,

$$
P B O_{t}= \begin{cases}\frac{B a(x(T))}{(1+\rho)^{T-t}} & t=1,2, \ldots, T \\ B a(y(t)) & y=x+1, x+2, \ldots ; \quad t=T+1, T+2, \ldots\end{cases}
$$

In (9), the valuation rate $\rho$ is set at a level reflecting the plan's expectation on pension asset investment returns and future inflows of supplementary contribution (Delong, Gerrard, and Haberman, 2008).

2. Following Maurer, Mitchell, and Rogalla (2009), we assume pension shortfall has the same amortization period as surplus. 
Equations (4) and (5) imply that the total fund available for investment at time $t \leq T, \Sigma_{i=1}^{n}$ $A_{i, t}$, can be expressed as

$$
\begin{aligned}
\sum_{i=1}^{n} A_{i, t} & =\sum_{i=1}^{n} A_{i, t-1}\left(1+r_{i, t}\right)+C+k\left[P B O_{t}-\sum_{i=1}^{n} A_{i, t-1}\left(1+r_{i, t}\right)-C\right] \\
& =(1-k) \sum_{i=1}^{n} A_{i, t-1}\left(1+r_{i, t}\right)+(1-k) C+k \cdot P B O_{t} .
\end{aligned}
$$

When $t>T, \sum_{i=1}^{n} A_{i, t}$ becomes

$$
\begin{aligned}
\sum_{i=1}^{n} A_{i, t}= & \sum_{i=1}^{n} A_{i, t-1}\left(1+r_{i, t}\right)+k\left[P B O_{t}-\sum_{i=1}^{n} A_{i, t-1}\left(1+r_{i, t}\right)+B \cdot t-T \hat{p}_{x, T}\right] \\
& -B \cdot t-T \hat{p}_{x, T} \\
= & (1-k) \sum_{i=1}^{n} A_{i, t-1}\left(1+r_{i, t}\right)-(1-k) B \cdot t-T \hat{p}_{x, T}+k \cdot P B O_{t}
\end{aligned}
$$

Assume the plan sponsor invests a proportion $w_{i}$ of pension funds in asset $i, i=1,2, \ldots, n$. The value of asset $i$ at time $t$ is

$$
\begin{aligned}
& A_{i, t}
\end{aligned}
$$

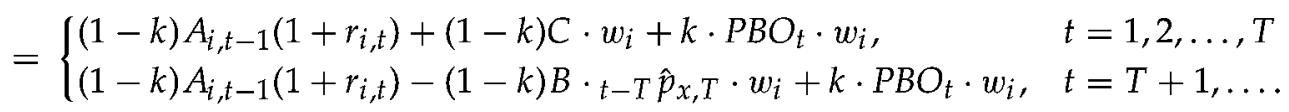

When $t=0, A_{i, 0}=w_{i} M$ for $i=1,2, \ldots, n$.

The plan makes periodic contributions to meet future benefit obligations. Those contributions constitute the plan's total pension cost. Following Maurer, Mitchell, and Rogalla (2009), we define total pension cost TPC as the present value of all normal contributions $C$, supplementary contributions $S C_{t^{\prime}}$ and withdrawals $W_{t}$ :

$$
T P C=\sum_{t=1}^{T} \frac{C}{(1+\rho)^{t}}+\sum_{t=1}^{\infty} \frac{S C_{t}\left(1+\psi_{1}\right)-W_{t}\left(1-\psi_{2}\right)}{(1+\rho)^{t}}
$$

where

$$
S C_{t}=\max \left\{k \cdot U L_{t^{\prime}} 0\right\}
$$


and

$$
W_{t}=\max \left\{-k \cdot U L_{t^{\prime}} 0\right\}
$$

The constants $\psi_{1}$ and $\psi_{2}$ are penalty factors on supplementary contributions $S C_{t}$ and withdrawals $W_{t^{\prime}}$ respectively. The penalty factor $\psi_{1}$ accounts for the opportunity cost the plan sponsor incurs due to unexpected mandatory supplementary contributions $S C_{t}$ that could have been invested in positive net present value projects. And $\psi_{2}$ takes into account the tax benefits the plan forgoes when it reduces the plan's normal contribution.

\section{Objective Function and Optimization Problem}

In our setting, the decision is taken at $t=0$ and the plan accumulates assets and asset returns plus contributions less liability cash flows at $t=1,2, \ldots$ until the final age of the lives. Following Colombo and Haberman (2005) and others, we consider a pension plan that aims at minimizing funding variation. Consistent with much of the DB pension literature, we model this risk with a quadratic objective function $J$ and measure supplementary contributions $k \cdot U L_{t}$ using the spread method for underfunding amortization in (66):

$$
J=E\left[\sum_{t=1}^{\infty}\left(\frac{U L_{t}}{(1+\rho)^{t}}\right)^{2}\right]
$$

This objective function is similar to Colombo and Haberman (2005) who minimize the variance of the two-tail funding status. As a departure, Kouwenberg (2001) defines the risk of a pension plan as the average squared one-tail underfundings (i.e., only penalizing supplementary contributions but not withdrawals) across the accumulation phase. However, as pointed out by Haberman and Sung (2005), an excessive solvency surplus held in the pension fund can be expensive because overfundings increase opportunity costs from forgone profitable investment opportunities and taxes on nondeductible surplus and contributions. Thus, in practice, the plan tries to avoid both over- and underfundings. The "two-tail" objective function in (14) is consistent with this goal.

We also impose three constraints respectively to control the total pension cost defined in (13), the expected total unfunded liability $E(T U L)$, and the downside risk of the total unfunded liability up to the terminal age of the retirees. The total unfunded liability up to the terminal age of the retirees, TUL, is defined as

$$
T U L=\sum_{t=1}^{\infty} \frac{U L_{t}}{(1+\rho)^{t}}
$$

To manage the downside risk of the total unfunded liability, following Bogentoft, Romeijn, and Uryasev (2001), we include a CVaR constraint on TUL at some percentile of interest $\alpha$, denoted as $\mathrm{CVar}_{\alpha}(T U L)$. 
Our optimization problem is to solve for the asset weights $w=\left[w_{1}, w_{2}, \ldots, w_{n}\right]$ and the normal contribution $C$, so as to minimize the funding variation $J$ throughout the whole life of the cohort:

$$
\begin{array}{ll}
\underset{w, C}{\text { Minimize }} & \mathrm{E}\left[\sum_{t=1}^{\infty}\left(\frac{U L_{t}}{(1+\rho)^{t}}\right)^{2}\right] \\
\text { subject to } & \mathrm{E}(T U L)=0 \\
& \mathrm{E}(T P C)=\zeta \\
& \mathrm{CVaR}_{\alpha}(T U L) \leq \tau \\
& 0 \leq w_{i} \leq 1, \quad i=1,2, \ldots, n \\
& \sum_{i=1}^{n} w_{i}=1 \\
& C \geq 0 .
\end{array}
$$

Different from Chang, Tzeng, and Miao (2003) who construct a weighted-average objective function that incorporates the first and second moments of underfunding, we impose the constraint $\mathrm{E}(T U L)=0$ and minimize the total funding variation. The $\mathrm{E}(T U L)=0$ constraint is also included in Delong, Gerrard, and Haberman (2008), Josa-Fombellida and RincónZapatero (2004), and others. In (15) the expected total pension cost $E(T P C)$ equals a preset target level $\zeta$. The constant $\tau$ specifies the upper limit of the $\alpha$-level CVaR constraint on TUL. The constraint $w_{i} \geq 0$ implies short-selling is not allowed.

As a robustness check, we compare our proposed model (15) with two alternative models, called problem (16) and problem (17), to investigate whether (15) can better balance funding variation, total pension cost, and funding downside risk. Problem (16) is to minimize $\mathrm{E}(T P C)$ subject to the $\mathrm{E}(T U L)$ and $\mathrm{CVar}_{\alpha}(T U L)$ constraints:

$$
\begin{array}{cl}
\begin{array}{c}
\text { Minimize } \\
w, C
\end{array} & \mathrm{E}(T P C) \\
\text { subject to } & \mathrm{E}(T U L)=0 \\
& \mathrm{CVaR}_{\alpha}(T U L) \leq \tau \\
& 0 \leq w_{i} \leq 1, \quad i=1,2, \ldots, n \\
& \sum_{i=1}^{n} w_{i}=1 \\
& C \geq 0 .
\end{array}
$$

The objective function of (16) is similar to that in Bogentoft, Romeijn, and Uryasev (2001) who minimize the total cost of funding a pension plan. 
Our second alternative model uses the same objective function as Haberman, Butt, and Megaloudi (2000) who define a weighted average function that addresses both funding variation and contribution rate risk. Specifically, their objective function is specified as:

$$
\theta \mathrm{E}\left[\sum_{t=1}^{\infty}\left(\frac{U L_{t}}{(1+\rho)^{t}}\right)^{2}\right]+(1-\theta) \mathrm{E}\left[\sum_{t=1}^{\infty}\left(\frac{C R_{t}}{(1+\rho)^{t}}\right)^{2}\right]
$$

where $\theta$ is a weighting factor to reflect the relative importance of the funding variation risk against the contribution rate risk. The contribution cash flow mismatch (i.e., the contribution rate risk), $C R_{t}$, is defined as

$$
C R_{t}= \begin{cases}C_{t}-C & t=1,2, \ldots, T \\ k \cdot U L_{t} & t=T+1, T+2, \ldots\end{cases}
$$

Here, $C_{t}$ is the plan's contribution at time $t, t \leq T$. Specifically, $C_{t}$ can be decomposed into two parts based on the normal contribution $C$ and the plan's underfunding $U L_{t}$ at time $t$, $t \leq T$ :

$$
C_{t}= \begin{cases}C+S C_{t} & \text { if } U L_{t} \geq 0 \\ C-W_{t} & \text { if } U L_{t} \leq 0\end{cases}
$$

Based on the objective function (17), our second alternative model has the same constraints as model (15). In Haberman, Butt, and Megaloudi (2000), the pension amortization factor $k$ is a choice variable. In the United States, in some cases, the pension firms do not have any leeway to flexibly determine their pension amortization period. ${ }^{3}$ Therefore, we do not solve optimization problem (17) with respect to $k$.

In the "Optimization Results" section, we will use a numerical example to compare our proposed model (problem (15)) with its alternatives (problem (16) and problem (17)). The results show that problem (15) and problem (17) realize the same optimal solutions when the amortization period of unfunded liabilities is fixed. Problem (16) achieves a lower $\mathrm{E}(\mathrm{TPC})$ than problem (15) but is at the expense of a higher funding variation. As discussed earlier, managing total pension cost, funding variation, and funding downside risk in an integrated way is important for the plan. Thus, in this article we rely on optimization problem (15), the model with a more holistic view, to perform further analysis.

3. For example, in Franzoni and Marin (2006), “According to accounting regulations, if a loss emerges in a pension plan as a consequence of reduced assets or increased liabilities and the loss is larger than 10 percent of the maximum between the two items, then the company is obliged to amortize the loss starting from the next fiscal year. According to SFAS 87, the amortization period will be the average remaining service period of active employees expected to receive benefits under the plan. If all, or almost all, of a plan's participants are inactive, the average remaining life expectancy of the inactive participants will be used instead of average remaining service." 


\section{Example}

Here we present a numerical example to show how to obtain the optimal normal contribution and asset allocation by solving optimization problem (15). We consider a cohort, all joining the plan at age $x_{0}=45$ at $t=0$, and retiring at $T=20$ when they reach age $x=65$. We estimate that the benefit payment rate is $c$ and number of survivors at age $x$ is $n$, so that $B=n c=\$ 10$ million. The plan will pay benefits to survivors at times $T+1, T+2$, . .. so for each of the $n$ retirees, the present value of benefits is $c \cdot a(x(T))$, and the aggregate present value is the sum of $n$ independent identically distributed benefits $n c \cdot a(x(T))=10$ $\cdot a(x(T))$ million at time $T$.

We assume the initial pension fund is $M=\$ 5$ million at $t=0$. The pension funds are invested in three assets: S\&P 500 index $A_{1, t^{\prime}}$ Merrill Lynch corporate bond index $A_{2, t^{\prime}}$ and 3-month T-bill $A_{3, t^{\prime}}$ with rates of returns $r^{1, t}, r_{2, t^{\prime}}$ and $r_{3, t}$ in period $t$, respectively. The plan sets the pension valuation rate at $\rho=0.08$ and the life annuity factor discount rate at $r=0.05$. It will amortize the unfunded liability over $m=7$ years. Moreover, following Maurer, Mitchell, and Rogalla (2009) we assume the penalty factors on supplementary contributions and withdrawals are both equal to $\psi_{1}=\psi_{2}=0.2$.

To model pension assets and mortality dynamics, we consider a probability space $(\Omega$, $\mathcal{F}, \mathbb{F}, \mathbb{P}$ ) with the filtration $\mathbb{F}=\left(\mathcal{F}_{t}\right)_{0 \leq t \leq \infty^{\prime}}$ where $\mathcal{F}_{t}$ is the information available up to time $t$. The filtration $\mathbb{F}$, denoted as $\mathbb{F}=\mathbb{F}^{F} \mathbb{F}^{M}$, consists of two subfiltrations where $\mathbb{F}^{F}$ contains information about the financial market and $\mathbb{F}^{M}$ contains information about the mortality evolution. We assume the two subfiltrations $\mathbb{F}^{F}$ and ${ }^{M}$ are independent. That is, the stochastic processes for assets and for mortality rates are independent.

\section{Financial Market Model}

We describe the process of the S\&P 500 index at time $t, A_{1, t^{\prime}}$ as the combination of a Brownian motion and a compound Poisson process as follows:

$\frac{\mathrm{d} A 1, t}{A 1, t}= \begin{cases}\alpha_{1} \mathrm{~d} t+\sigma_{1} \mathrm{~d} W_{1 t^{\prime}} & \text { if the Poisson event does not occur at time } t \\ \left(\alpha_{1}-\lambda_{1} k_{1}\right) \mathrm{d} t+\sigma_{1} \mathrm{~d} W_{1 t}+\left(Y_{1}-1\right), & \text { if the Poisson event occurs at time } t\end{cases}$

The constant $\alpha_{1}$ is the drift of the S\&P 500 index; $\sigma_{1}$ is its instantaneous volatility, conditional on no jumps. $W_{1 t}$ is a standard Brownian motion with mean 0 and variance $t . \lambda_{1}$ is the mean number of arrivals per unit time of a Poisson process $N_{t}^{1}$. The Poisson random measure $N_{t}^{1}$ counts the number of jumps of a particular size $\left(Y_{1}-1\right)$ during a time interval of $(0$, t). A dramatic change (or a jump) in the value of S\&P 500 index can be driven by the events such as the stock market downturn of 2002 or the recent financial crisis in the late 2000s. The Poisson process $N_{t}^{1}$ and the standard Brownian motion $W_{1 t}$ are independent. The parameter $k_{1}$ is $k_{1} \equiv \mathrm{E}\left(Y_{1}-1\right)$, where $\mathrm{E}\left(Y_{1}-1\right)$ is the expected percentage change in the S\&P 500 index if a Poisson event occurs.

The S\&P 500 index, $A_{1, t^{\prime}}$ will be continuous most of the time with finite jumps occurring at discrete points of time. The part " $\sigma_{1} \mathrm{~d} W_{1 t}$ " describes the instantaneous part of an 
unanticipated "normal" S\&P index change, and " $Y_{1}-1$ " captures the "abnormal" shocks. If $\lambda_{1}=0$, then $Y_{1}-1=0$ and it is the same as the standard stochastic model without jumps. If $\alpha_{1}, \sigma_{1}, \lambda_{1}$, and $k_{1}$ are constants, we can solve the differential equation (20) as

$$
\frac{A_{1, t}}{A_{1,0}}=\exp \left[\left(\alpha_{1}-\frac{1}{2} \sigma_{1}^{2}-\lambda_{1} k_{1}\right) t+\sigma_{1} W_{1 t}\right] Y\left(N_{t}^{1}\right)
$$

The cumulative jump size $Y\left(N_{t}^{1}\right)=1$ if $N_{t}^{1}=0$ and $Y\left(N_{t}^{1}\right)=\prod^{N_{t}^{1}}{ }_{j=1} Y_{1 j}$ for $N_{t}^{1} \geq 1$, where the jump sizes, $Y_{1 j}$ for $j=1,2 \ldots$, are independent and identically distributed as lognormal random variables so that $\log Y_{1 j}$ is a standard normal random variable with mean parameter $m_{1}$ and volatility parameter $s_{1}$.

From (21), we can derive the S\&P 500 index value $A_{1^{\prime} t+\Delta^{\prime}}$ given $\mathcal{F}_{t}$ resulting in

$$
A_{1, t+\Delta} \mid \mathcal{F}_{t}=A_{1, t} \exp \left[\left(\alpha_{1}-\frac{1}{2} \sigma_{1}^{2}-\lambda_{1} k_{1}\right) \Delta+\sigma_{1} \Delta W_{1 t}\right] \prod_{j>N_{t}^{1}}^{N_{t+\Delta}^{1}} Y_{1 j}
$$

where $\mathcal{F}_{t}$ is the information set up to time $t$.

Similarly, the Merrill Lynch corporate bond index $A_{2, t+\Delta}$ given $\mathcal{F}_{t}$ is defined as follows:

$$
A_{2, t+\Delta} \mid \mathcal{F}_{t}=A_{2, t} \exp \left[\left(\alpha_{2}-\frac{1}{2} \sigma_{2}^{2}-\lambda_{2} k_{2}\right) \Delta+\sigma_{2} \Delta W_{2 t}\right] \prod_{j>N_{t}^{2}}^{N_{t+\Lambda}^{2}} Y_{2 j}
$$

where $\alpha_{2}$ is the drift of the Merrill Lynch corporate bond index; $\sigma_{2}$ is the instantaneous volatility, conditional on no jumps. $W_{2 t}$ is a standard Brownian motion with mean 0 and variance $t$. The jump sizes are independent lognormal random variables with parameters $m_{2}$ and $s_{2}$. The jumps $Y_{1 j}$ and $Y_{2 i}$ are independent for all $i$ and $j$. The covariance of $W_{1 t}$ and $W_{2 t}$ is

$$
\operatorname{Cov}\left(W_{1,}, W_{2 t}\right)=\rho_{12} \sigma_{1} \sigma_{2} t
$$

where $\rho_{12}$ is the parameter measuring the dependence of the stock and bond indices.

In addition, we assume the 3-month T-bill evolves according to a geometric Brownian motion as follows:

$$
\frac{\mathrm{d} A_{3, t}}{A_{3, t}}=\alpha_{3} \mathrm{~d} t+\sigma_{3} \mathrm{~d} W_{3 t}
$$

where $\alpha_{3}, \sigma_{3}$, and $W_{3 t}$ are the drift, volatility, and standard Brownian motion of the 3-month T-bill. The differential equation (25) can be solved as

$$
A_{3, t+\Delta} \mid \mathcal{F}_{t}=A_{3, t} \exp \left[\left(\alpha_{3}-1 / 2 \sigma_{3}^{2}\right) \Delta+\sigma_{3} \Delta W_{3 t}\right]
$$


Table 1. Maximum Likelihood Parameter Estimates of Three Pension Assets

\begin{tabular}{lclcll}
\hline Parameter & Estimate & Parameter & Estimate & Parameter & Estimate \\
\hline$\alpha_{1}$ & 0.1081 & $\alpha_{2}$ & 0.0794 & $\alpha_{3}$ & 0.0523 \\
$\sigma_{1}$ & 0.1069 & $\sigma_{2}$ & 0.0481 & $\sigma_{3}$ & 0.0094 \\
$\lambda_{1}$ & 0.2946 & $\lambda_{2}$ & 0.0080 & & \\
$m_{1}$ & -0.0272 & $m_{2}$ & -0.0744 & & 0.3380 \\
$s_{1}$ & 0.0536 & $s_{2}$ & 0.0000 & $\rho_{12}$ & 0.3380 \\
\hline
\end{tabular}

We further assume the 3-month T-bill is uncorrelated with the S\&P 500 index and the Merrill Lynch corporate bond index,

$$
\operatorname{Cov}\left(W_{1 t^{\prime}} W_{3 t}\right)=0, \text { and } \operatorname{Cov}\left(W_{2 t^{\prime}} W_{3 t}\right)=0
$$

We estimate models (22), (23), and (26) based on monthly data from March 1988 to December 2010. For the S\&P 500 index and the Merrill Lynch corporate bond index, we rely on the time series data provided by DataStream. The monthly 3-month T-bill rates are obtained from FRED at Federal Reserve Bank of St. Louis. ${ }^{4}$ We use the monthly data to increase the number of observations for model calibration. Since we are interested in annual returns, we convert our monthly maximum likelihood estimates to annual estimates. Those annual estimates are presented in Table 1.

Table 1 indicates that the S\&P 500 index has a higher expected log return $\left(\alpha_{1}=0.1081\right)$ and volatility $\left(\sigma_{1}=0.1069\right)$ than the Merrill Lynch corporate bond index $\left(\alpha_{2}=0.0794, \sigma_{2}=0.0481\right)$ and the 3-month T-bill $\left(\alpha_{3}=0.0523, \sigma_{3}=0.0094\right)$. The expected number of jumps per year for the stock index is $\lambda_{1}=0.2946$. For the corporate bond index the expected number of jumps per year is $\lambda_{2}=0.0080$. Given a jump event occurs, the expected logarithm of the jump size is $m_{1}=-0.0272$ for the stock index and $m_{2}=-0.0744$ for the bond index. In addition, the stock index and the corporate bond index are positively correlated with correlation parameter $\rho_{12}=0.3380$.

Stochastic Mortality Model. We apply the Lee and Carter (1992) model to describe pension mortality rates. This model incorporates both the age-specific mortality variation and the general time trend of mortality evolution for all ages. In this form of the LeeCarter model, the logarithm of the 1 -year death rate $q_{x, t}$ at age $x(x=0,1,2, \ldots)$ in year $t$ $(t=1,2, \ldots, K)$ is

$$
\ln q_{x, t}=a_{x}+b_{x} \gamma_{t}+\varepsilon_{x, t}
$$

where $a_{x}$ and $b_{x}$ are the age-specific parameters.

The transitory shock $\varepsilon_{x, t}$ is a normally distributed variable with zero mean. The time series common risk factor $\gamma_{t}$ affects the mortality rates of all ages in year $t$. Lee and Carter (1992)

4. http://research.stlouisfed.org 
assume $\gamma_{t}$ follows a random walk with drift $g$,

$$
r_{t}=\gamma_{t-1}+g+e_{t}
$$

where the error term $e_{t}$ is normally distributed with a zero mean and a variance $\sigma_{\gamma}$.

The solution of (27) is not unique so the following two constraints are imposed:

$$
\sum_{x} b x=1 \text { and } \sum_{t} r_{t}=0
$$

These two constraints imply that the intercept $a_{x}$ is simply the empirical average of age $x$ over time:

$$
a_{x}=\frac{\sum_{t=1}^{K} \ln q_{x, t}}{K}
$$

where $K$ is the length of the time series of mortality data. We follow the Lee and Carter's (1992) method by incorporating singular value decomposition to estimate $b_{x}$ for each age $x$ and $\gamma_{t}$ for each year $t$.

We assume the pension plan has the same mortality experience as that of the U.S. male population and it estimates model (27) following the Lee and Carter (1992) procedure. The tables for years 1901 to 1999 are from the Human Life Table Database and the tables for 2000 to 2007 are from the Human Mortality Database, published by the University of California, Berkeley, and Max Planck Institute for Demographic Research. ${ }^{5}$ The estimated $\gamma_{t}$ are shown in Figure 1.6 Based on the ages $x=0,1,2, \ldots$, and the time series of $\gamma_{t}$ where $t=1901,1902, \ldots, 2006,2007$, we obtain $g=-0.20$ and $\sigma_{\gamma}=0.63$ for (28).

Now consider a cohort who joins the plan at age $x_{0}=45$ in year 2007. After setting year 2007 as the base year $t=0$, we forecast the mortality rates $q_{45+t, t}$ for $t=1, \ldots, T, T+1, \ldots$ .We first simulate the error term $e_{t}$ and then add the constant $g=-0.20$ to each simulated $e_{t}$ to get a $\gamma_{t}$ where $t=1,2, \ldots, T, T+1, \ldots$ Given the estimated $a_{45+t}$ 's and $b_{45+t}$ 's and the simulated $\gamma_{t}^{\prime}$ s, we use model (27) to calculate simulated future mortality rates

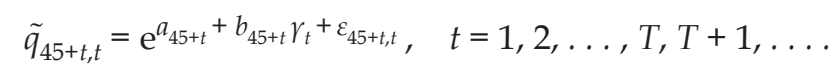

The forecasted 1-year survival probability is

$$
\tilde{p}_{45+t, t}=1-\tilde{q}_{45+t, t}
$$

5. Available at http://www.mortality.org or http://www.humanmortality.de (data downloaded on February 25, 2011).

6. To conserve space, the parameter estimates of $a_{x}$ and $b_{x}$ are not reported but available upon request. 


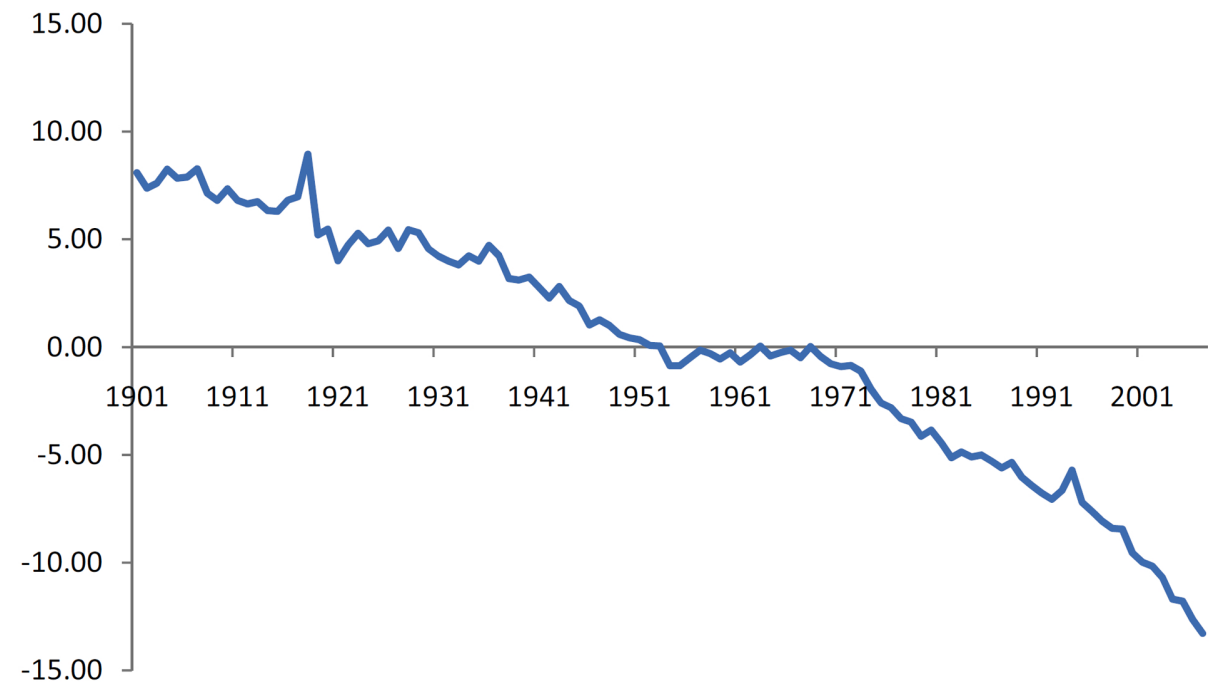

Figure 1. Estimated Time Series Common Risk Factor $\gamma_{t}$ Shown in the Vertical Axis for Year $t=1901$, 1902, . . . 2006, 2007 in the Horizontal Axis.

This pension cohort will retire at time $t=T=20$ when all pensioners reach age $x=45+$ $t=65$. Based on the simulated survival rates forecasted with the Lee-Carter model, we calculate the conditional expected value of the life annuity $a(x(T))$ using (2):

$$
\begin{aligned}
a(x(T)) & =\sum_{s=1}^{\infty} v^{s} \mathrm{E}\left[s \tilde{p}_{x, T} \mid \tilde{p}_{x, T}, \tilde{p}_{x+1, T+1}, \ldots, \tilde{p}_{x+s-1, T+s-1}\right] \\
& =\sum_{s=1}^{\infty} v^{s} \mathrm{E}\left[{ }_{s} \tilde{p}_{65,20} \mid \tilde{p}_{65,20}, \tilde{p}_{66,21} \ldots, \tilde{p}_{65+s-1,20+s-1}\right]
\end{aligned}
$$

where

$$
{ }_{s} \tilde{p}_{65,20}=\tilde{p}_{65,20} \cdot \tilde{p}_{66,21} \ldots \tilde{p}_{65+s-1,20+s-1} .
$$

After retirement $T$, we use (3) to determine the value of the life annuity $a(y(t))$ for $y>x=$ 65 and $t>T=20$,

$$
a(y(t))=\sum_{s=1}^{\infty} v^{s} \mathrm{E}_{s} \tilde{p}_{y, t} \mid \tilde{p}_{y, t}, \tilde{p}_{\left.y+1, t+1, \ldots, \tilde{p}_{y+s-1, t+s-1}\right]}
$$

where

$$
{ }_{s} \tilde{p}_{y, t}=\tilde{p}_{y, t} \cdot \tilde{p}_{y+1, t+1} \ldots \tilde{p}_{y+s-1, t+s-1}
$$


Table 2. Model Comparison

\begin{tabular}{lcccccccc}
\hline & $C$ & $w_{1}$ & $w_{2}$ & $w_{3}$ & $\mathrm{E}(\mathrm{TPC})$ & $\mathrm{CVaR}_{95 \%}(\mathrm{TUL})$ & $\mathrm{E}(\mathrm{TUL})$ & $J$ \\
\hline Initial & 1.00 & $33.33 \%$ & $33.33 \%$ & $33.33 \%$ & 15.01 & 69.66 & 3.79 & 984.20 \\
Problem (15) & 1.07 & $17.13 \%$ & $69.82 \%$ & $13.06 \%$ & 15.01 & 59.63 & 0.00 & 935.63 \\
Problem (16) & 1.06 & $21.16 \%$ & $61.40 \%$ & $17.45 \%$ & 14.90 & 59.63 & 0.00 & 942.57 \\
\hline
\end{tabular}

With the values of $a(x(T))$ and $a(y(t))$, the value of the pension liability $P B O_{t}$ at time $t, t=0$, $1, \ldots$ can be calculated from (9).

Optimization Results. We set year 2007 as the base year $t=0$ and ran a Monte Carlo simulation with 1,000 iterations to generate returns for three financial assets $A_{i, t} i=1,2,3$ and future liabilities $\mathrm{PBO}_{t}$ for $t=1,2, \ldots 7$ Initially, we assume the plan invests equally in the three assets, that is, $w_{1}=w_{2}=w_{3}=1 / 3$ and makes an annual normal contribution $C$ $=1$. This strategy leads to an expected total pension cost $E(T P C)=15.01$. As shown in the row labeled "Initial" in Table 2, the initial strategy has a 95 percent CVaR of TUL equal to $\mathrm{CVaR}_{95 \%}(T U L)=69.66$ and an expected TUL equal to $\mathrm{E}(T U L)=3.79$. The sum of all funding variations throughout the whole lives of the pension cohort equals $J=984.20$.

Next we solve the optimization problem (15) to obtain the optimal asset allocation and normal contribution. Based on our experiments, given the same $\zeta=15.01$ as the $\mathrm{E}(\mathrm{TPC})$ of the initial case, we find that the lowest feasible upper limit of $\mathrm{CVaR}_{95 \%}$ (TUL) for (15) equals $\tau=59.63$. With the combination of $\zeta=15.01$ and $\tau=59.63$, the optimal solution for (15) is shown in the row labeled "Problem (15)" in Table 2. To achieve the lowest funding variation, on average, the plan should invest $w_{1}=17.13$ percent of the funds in the S\&P 500 index, $w_{2}=69.82$ percent in the Merrill Lynch corporate bond index, and the remaining funds should be invested in the 3-month T-bill with $w_{3}=13.06$ percent. In addition, given $\mathrm{E}(T U L)=0$, the optimal normal contribution equals $C=\$ 1.07$ million per year.Our optimization problem (15) achieves $\mathrm{E}(T U L)=0$ and it has a lower funding downside risk $\mathrm{CVaR}_{95 \%}($ TUL $)=59.63$ and a lower total funding variation $J=935.63$ than the initial case with $\mathrm{CVaR}_{95 \%}(T U L)=69.66$ and $J=984.20$.

Our results show that problem (17) with different $\theta$ s has the same optimal asset allocation and normal contribution as our proposed model (15) shown in Table 2 . This is not surprising because when $U L_{t}>0$, the supplementary contribution $S C_{t}$ equals $k \cdot U L_{t}$ and when $U L_{t}$ $<0$, the plan has a withdrawal $W_{t}=-k \cdot U L_{t}$. That is, $U L_{t}$ determines the deviation of the actual periodic contribution $C_{t}$ from the normal contribution $C$ in (19). In fact, when the

7. In our numerical example we only consider three assets but our model can handle a higher number of assets. 
pension amortization factor $k$ is specified at a given level, the objective function of problem (17) can be restated as:

$$
\begin{aligned}
\theta \mathrm{E} & {\left[\sum_{t=1}^{\infty}\left(\frac{U L_{t}}{(1+\rho)^{t}}\right)^{2}\right]+(1-\theta) \mathrm{E}\left[\sum_{t=1}^{\infty}\left(\frac{C R_{t}}{(1+\rho)^{t}}\right)^{2}\right] } \\
& =\theta \mathrm{E}\left[\sum_{t=1}^{\infty}\left(\frac{U L_{t}}{(1+\rho)^{t}}\right)^{2}\right]+(1-\theta) \mathrm{E}\left[\sum_{t=1}^{\infty}\left(\frac{k \cdot U L_{t}}{(1+\rho)^{t}}\right)^{2}\right] \\
& =\left(\theta+(1-\theta) k^{2}\right) \mathrm{E}\left[\sum_{t=1}^{\infty}\left(\frac{U L_{t}}{(1+\rho)^{t}}\right)^{2}\right],
\end{aligned}
$$

which is the same as the objective function of problem (15) scaled by a constant $(\theta+(1-$ $\theta) k^{2}$. This explains why problem (15) and problem (17) have the same solution and our setting is equivalent to Haberman, Butt, and Megaloudi (2000) when $k$ is a constant.

Finally, we compare problem (16) with problem (15). To make comparison comparable, we set the constraints in (16),

$$
\mathrm{E}(T U L)=0 \text { and } \mathrm{CVaR}_{95 \%}(T U L) \leq 59.63,
$$

which are the same as those in our example for (15). Table 2 shows that problem (16) has a little lower $\mathrm{E}(T P C)$ but a higher total funding variation $J$ than problem (15). This can be explained by the fact that problem (16) aims at minimizing $\mathrm{E}(T P C)$ but does not manage the total funding variation. Since both funding variation and downside risk are the major concerns for pension risk management, in the following discussion, we focus on problem (15) that takes a more balanced view.

\section{Longevity Risks}

Mortality has improved over time. The example in the "Stochastic Mortality Model" section, which we call the base case, shows that on average the value of the common risk factor $\gamma_{t}$ decreases by 0.20 across all ages per year from 1901 to 2007 (i.e., $g=-0.20$ ). However, the tendency of pension participants to live longer than what the historical data suggest has been increasingly attracting the attention of plan sponsors, regulators, actuaries, academics, and others. This is so-called longevity risk, the risk that the mortality of pensioners improves at a higher rate than expectation. Accordingly, an interesting question for the pension plan is: if the mortality improves more than the base case with $g=$ -0.20 , how will it change the optimal asset allocation and normal contribution?

In particular, we consider mortality dynamics under which the pension liability is an increasing function of survival probabilities, as higher survival probabilities will yield a longer lifetime and a longer duration of annuity payments. In a sensitivity analysis of the plan's total pension cost to the longevity risk, we change the drift of the common risk factor $\gamma_{t}$ in the Lee and Carter (1992) model in an equal interval of 0.05 from the base case $g=-0.20$ to $g=-0.40$. A more negative $g$ means a greater level of mortality improvement. 
Table 3. Optimal Pension Normal Contribution and Asset Allocation Strategies With $\mathrm{E}(T$ TUL $)=0$ and $\mathrm{CVaR}_{95 \%}(T U L)=59.63$ and Different Assumptions on Mortality Improvement Parameter $g$ in the Lee and Carter (1992) Model.

\begin{tabular}{ccccccc}
\hline$g$ & $C$ & $w_{1}$ & $w_{2}$ & $w_{3}$ & $\mathrm{E}(\mathrm{TPC})$ & $J$ \\
\hline-0.20 & 1.07 & $17.13 \%$ & $69.82 \%$ & $13.06 \%$ & 15.01 & 935.63 \\
-0.25 & 1.24 & $26.83 \%$ & $38.37 \%$ & $34.80 \%$ & 16.60 & 941.38 \\
-0.30 & 1.37 & $28.26 \%$ & $28.64 \%$ & $43.10 \%$ & 17.86 & 954.88 \\
-0.35 & 1.53 & $29.49 \%$ & $17.77 \%$ & $52.74 \%$ & 19.36 & 955.44 \\
-0.40 & 1.59 & $28.78 \%$ & $17.29 \%$ & $53.93 \%$ & 19.97 & 974.56 \\
\hline
\end{tabular}

Next, given a level of funding downside risk, we investigate how the optimal normal contribution, asset allocation, and total pension cost will change with the life expectancy of pensioners. Specifically, we solve a problem that minimizes

$$
J=E\left[\sum_{t=1}^{T}\left(\frac{U L_{t}}{(1+\rho)^{t}}\right)^{2}\right]
$$

subject to the constraint $\mathrm{E}(\mathrm{TUL})=0$ and a 95 percent $\mathrm{CVaR}$ constraint on total unfunded liability, CVaR95\%(TUL). To make our comparison comparable, we specify this CVaR constraint as

$$
\mathrm{CVaR}_{95 \%}(T U L)=59.63
$$

which ensures the unexpected mortality improvement cases with different $g s$ have the same downside risk as the base case with $g=-0.20$.

Notice we do not impose the constraint $\mathrm{E}(T P C)=\zeta$ when we examine longevity risk effects due to regulatory considerations. Theoretically, as pensioners live longer, to achieve a target expected total pension cost $\mathrm{E}(T P C)$, the pension plan has to make less normal contribution and invest a higher proportion of funds in risky assets (Josa-Fombellida and Rincón-Zapatero, 2004). However, in reality, regulators will not allow an underfunded plan to reduce its contribution and speculate on risky assets simply to realize a target $\mathrm{E}(\mathrm{TPC})$. Instead, $\mathrm{E}(T P C)$ has to be adjusted upward to reflect a higher longevity risk as shown in Table 3.

In Table 3, the adverse effect of an unexpected mortality improvement is captured by the change in $\mathrm{E}(T P C)$ paid by the plan. As $g$ decreases from -0.20 to $-0.40, \mathrm{E}(T P C)$ significantly increases from 15.01 to 19.97, a 33 percent rise. In addition, we observe a higher life expectancy of the pensioners (with a more negative $g$ ) leads to a higher optimal normal contribution: $C$ increases from 1.07 with $g=-0.20$ to 1.59 with $g=-0.40$. Also notice that as the mortality improves, the plan needs to invest more in the low-risk asset to satisfy the downside risk constraint $\mathrm{CVaR}_{95 \%}(T U L)=59.63$. The proportion of total funds invested in the 3-month T-bill dramatically increases from 13.06 percent with $g=-0.20$ to 53.93 percent with $g=-0.40$. 


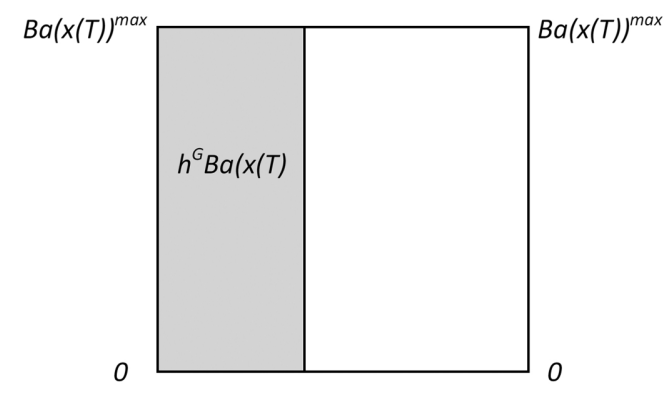

Figure 2. The Ground-Up Hedging Strategy; $B a(x(T))^{\max }$ Stands for the Highest Possible Pension Liability $B a(x(T))$; This Strategy Hedges a Proportion $h^{G}\left(0 \leq h^{G} \leq 1\right)$ of the Pension Liability $B a(x(T))$, Represented by the Shaded Area $h^{G} B a(x(T))$

It is difficult for a plan to predict future mortality rates. The resulting uncertainty can immediately affect the stability of the pension plan through, at least, wrong asset allocations and inappropriate normal contributions. However, if the pension plan can hedge its longevity risk, it will suffer much less from financial distress due to unexpected mortality improvement. Therefore, we turn our attention to analyzing optimal hedging decisions. In the next two sections, we discuss two pension longevity risk hedging strategies: the ground-up hedging strategy and the excess-risk hedging strategy.

\section{Managing Pension Longevity Risks with the Ground-Up Hedging Strategy}

In this section, we study the optimal hedging decision for a pension plan when it implements the ground-up hedging strategy. This strategy transfers a proportion $h^{G}$ of the pension liability, represented by the shaded area $h^{G} \mathrm{Ba}(x(T))$ in Figure 2, to a hedge provider where $0 \leq h^{G} \leq 1$. The hedge provider will pay a proportion $h^{G}$ of benefits due to retirees at time $T+1, T+2, \ldots$.

Specifically, let $\mathrm{E}[\mathrm{B} a(x(T))]=B \bar{a}(x(T))$. At time $t=0$, the pension plan starts with an accumulated fund $M$ and cedes a portion $h^{G}$ of the plan liability $B a(x(T))$ to a third party (e.g., longevity-security investors), who accepts the obligation for a price equal to ${ }^{8}$

$$
H P^{G}=\frac{h^{G}\left(1+\delta^{G}\right) B \bar{a}(x(T))}{(1+\rho)^{T}}
$$

where $\delta^{G}$ is the unit hedge cost. The unit hedge cost $\delta^{G}$ covers risk premium, issuance cost, and administrative expenses of the longevity risk taker as well as the time and resources

8. In our article, the price $H P^{G}$ for the ground-up strategy (or $H P^{E}$ for the excess-risk strategy) is the market price determined by the capital market. We assume the plan takes the price $H P^{G}\left(\right.$ or $\left.H P^{E}\right)$ as given for its optimal hedging decision. An example of $H P^{G}$ is the annuity premium General Motors paid Prudential to reduce its pension obligations (Kelly, 2012). 
the plan spends to transfer its longevity risk. As a result, the pension plan retains a liability of $\left(1-h^{G}\right) P B O_{t}^{G}$ and its liability at time $t$ becomes

$$
P B O_{t}^{G}= \begin{cases}\frac{\left(1-h^{G}\right) B a(x(T))}{(1+\rho)^{T-t}} & t=1,2, \ldots, T \\ \left(1-h^{G}\right) B a(y(t)) & t=T+1, T+2, \ldots\end{cases}
$$

Meanwhile, the plan invests in the capital market to generate investment income. Given that the plan hedges a fraction $h^{G}$ of its pension liability by paying $H P^{G}$, the total amount of pension assets available for investment at $t=0$ is

$$
P A_{0}^{G}=M^{G}=M-H P^{G}
$$

which is lower than that in the no-hedge case where $P A_{0}=M$. The balance equation under the ground-up hedging strategy changes to:

$$
\sum_{i=1}^{n} A_{i, t}^{G}= \begin{cases}P A_{t}^{G}+C^{G}+k \cdot U L_{t}^{G} & t=1,2, \ldots, T \\ P A_{t}^{G}+k \cdot U L_{t}^{G}-\left(1-h^{G}\right) B \cdot{ }_{t-T} \hat{p}_{x, T} & t=T+1, T+2, \ldots\end{cases}
$$

The underfunding liability equals

$$
U L_{t}^{G}= \begin{cases}P B O_{t}^{G}-P A_{t}^{G}-C^{G} & t=1,2, \ldots, T \\ P B O_{t}^{G}-P A_{t}^{G}+\left(1-h^{G}\right) B \cdot{ }_{t-T} \hat{p}_{x, T} & t=T+1, T+2, \ldots\end{cases}
$$

where $P A_{t}^{G}$ is the value of pension assets before the plan makes contributions and pays survival benefits at time $t$.

Similar to (10), the total fund available for investment at time $t \leq T, \sum_{i=1}^{n} A_{i, t}^{G}$ in (35) for the ground-up strategy equals

$$
\sum_{i=1}^{n} A_{i, t}^{G}=(1-k) \sum_{i=1}^{n} A_{i, t-1}^{G}\left(1+r_{i, t}\right)+(1-k) C^{G}+k \cdot P B O_{t}^{G}
$$

When $t>T, \quad \sum_{i=1}^{n} A_{i, t}^{G}$ becomes

$$
\sum_{i=1}^{n} A_{i, t}^{G}=(1-k) \sum_{i=1}^{n} A_{i, t-1}^{G}\left(1+r_{i, t}\right)-(1-k)\left(1-h^{G}\right) B \cdot t-T \hat{p}_{x, T}+k \cdot P B O_{t}^{G}
$$


Assume the plan sponsor invests a proportion $w_{i}^{G}$ of pension funds in asset $i, i=1,2, \ldots$, $n$. The value of asset $i$ at time $t$ is

$$
A_{i, t}^{G}= \begin{cases}(1-k) A_{i, t-1}^{G}\left(1+r_{i, t}\right)+(1-k) C^{G} \cdot w_{i}^{G}+k \cdot P B O_{t}^{G} \cdot w_{i}^{G} & t=1,2, \ldots, T \\ (1-k) A_{i, t-1}^{G}\left(1+r_{i, t}\right)-(1-k)\left(1-h^{G}\right) B \cdot t-T \hat{p}_{x, T} \cdot w_{i}^{G} & \\ \quad+k \cdot P B O_{t}^{G} \cdot w_{i}^{G} & t=T+1, \ldots\end{cases}
$$

When $t=0, A_{i, 0}^{G}=w_{i} M^{G}$ for $i=1,2, \ldots, n$.

The optimal investment and contribution policy is subject to a total pension cost constraint. Compared to the no-hedge case, the ground-up hedging strategy has an additional cost component - the hedge cost. For each dollar hedged, the plan pays $\delta^{G}$ dollars to set up the contract. After hedging $h^{G} B a(x(T))$ of the plan liability, the plan pays a total pension cost with the present value at time 0 equal to:

$$
T P C^{G}=\frac{h^{G} \delta^{G} B \bar{a}(x(T))}{(1+\rho)^{T}}+\sum_{t=1}^{T} \frac{C^{G}}{(1+\rho)^{t}}+\sum_{t=1}^{\infty} \frac{S C_{t}^{G}\left(1+\psi_{1}\right)-W_{t}^{G}\left(1-\psi_{2}\right)}{(1+\rho)^{t}}
$$

where $h^{G} \delta^{G} B \bar{a}(x(T)) /(1+\rho)^{T}$ is the present value of the total hedge cost.

\section{How to Transfer Longevity Risk with the Ground-Up Hedging Strategy?}

The optimization problem of the pension plan with respect to the asset weights $w^{G}=\left[w_{1}^{G}\right.$, $\left.w_{2}^{G}, \ldots, w_{n}^{G}\right]$, normal contribution $C^{G}$, and hedge ratio $h^{G}$ is expressed as:

$$
\begin{aligned}
\underset{w^{G}, C^{G}, h^{G}}{\text { Minimize }} & \mathrm{E}\left[\sum_{t=1}^{\infty}\left(\frac{U L_{t}^{G}}{(1+\rho)^{t}}\right)^{2}\right] \\
& \mathrm{E}\left(T U L^{G}\right)=0 \\
& \mathrm{E}\left(T P C^{G}\right)=\zeta \\
& \mathrm{CVaR}_{\alpha}\left(T U L^{G}\right) \leq \tau \\
& \frac{h^{G}\left(1+\delta^{G}\right) B \bar{a}(x(T))}{(1+\rho)^{T}} \leq M \\
& 0 \leq h^{G} \leq 1 \\
& 0 \leq w_{i}^{G} \leq 0, \\
& \sum_{i=1}^{n} w_{i}^{G}=1 \\
& C^{G} \geq 0,
\end{aligned}
$$


Table 4. Optimal Ground-Up Hedging Strategies with Different Assumptions on Hedge Cost Parameter $\delta^{G}$ Given $\zeta=15.01, \tau=59.63$, and $g=-0.20$

\begin{tabular}{cccccccc}
\hline$\delta^{G}$ & $C^{G}$ & $w_{1}^{G}$ & $w_{2}^{G}$ & $w_{3}^{G}$ & $h^{G}$ & $\mathrm{CVaR}_{95 \%}\left(\mathrm{TUL} L^{G}\right)$ & $J^{G}$ \\
\hline 0.000 & 1.09 & $19.37 \%$ & $77.87 \%$ & $2.76 \%$ & $21 \%$ & 51.82 & 917.18 \\
0.010 & 1.08 & $20.07 \%$ & $76.89 \%$ & $3.04 \%$ & $21 \%$ & 52.28 & 925.83 \\
0.020 & 1.07 & $18.50 \%$ & $74.80 \%$ & $6.70 \%$ & $13 \%$ & 55.31 & 932.86 \\
0.025 & 1.07 & $17.95 \%$ & $72.33 \%$ & $9.72 \%$ & $7 \%$ & 57.25 & 934.83 \\
0.030 & 1.07 & $17.24 \%$ & $69.96 \%$ & $12.79 \%$ & $1 \%$ & 59.45 & 935.61 \\
0.035 & 1.07 & $17.13 \%$ & $69.82 \%$ & $13.06 \%$ & $0 \%$ & 59.63 & 935.63 \\
\hline
\end{tabular}

where $T U L^{G}=\sum_{t=1}^{\infty} \frac{U L_{t}^{G}}{(1+\rho)^{t}}$. The constraint

$$
\frac{h^{G}\left(1+\delta^{G}\right) B \bar{a}(x(T))}{(1+\rho)^{T}} \leq M
$$

ensures the hedge price does not exceed the pension fund at $t=0$. That is, the plan does not borrow money to pay for the cost of risk transferred.

\section{Example}

Here we continue the example in the previous "Example" section, but now assume that the plan implements a ground-up hedging strategy.We set $E(T P C)$ and the upper bound of $\mathrm{CVaR}_{\alpha}(T U L)$ at the same levels as those in the optimal case without hedging (see the row labeled "Problem (15)" in Table 2). The results are shown in Table 4. When hedging is costless $\left(\delta^{G}=0\right)$, subject to the total pension cost constraint $\zeta=15.01$ and the upper limit of the TUL 95 percent CVaR constraint $\tau=59.63$, the plan hedges 21 percent of the pension liability. This allows the plan to achieve a total funding variation

$$
J^{G}=\mathrm{E}\left[\sum_{t=1}^{\infty}\left(\frac{U L_{t}^{G}}{(1+\rho)^{t}}\right)^{2}\right]=917.18
$$

which is lower than that in the no-hedge case $J^{G}=935.63$ when $h^{G}=0$.

When the plan hedges, it incurs an explicit cost and an implicit cost. The explicit cost is the unit hedge cost $\delta^{G}$. The implicit cost arises from the reduced fund available for investment since the fund available for investment decreases from $M$ to $M^{G}$. The plan sacrifices a higher expected return from the risky asset class in exchange for a lower longevity risk. However, longevity risk hedging is attractive only if its benefits exceed costs. Table 4 shows a negative relation between the hedge ratio $h^{G}$ and the unit hedge $\operatorname{cost} \delta^{G}$. The plan chooses to hedge less as hedging becomes more expensive. As $\delta^{G}$ increases from 0 to 0.03 , the hedge ratio $h^{G}$ decreases from 21 to 1 percent. When $\delta^{G}$ goes above 0.03 , no longevity 


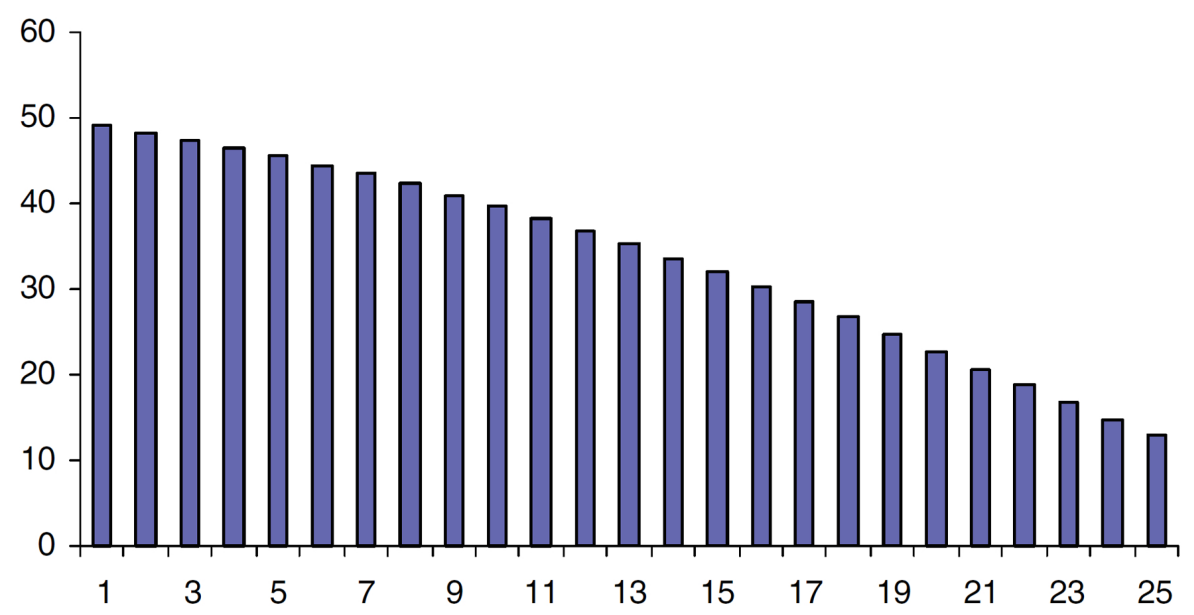

Figure 3. Coverage of the EIB Longevity Bond. Note: The solid filled bars show the protection provided by the EIB longevity bond each year (millions in pounds); the horizontal axis represents time in years.

risk will be ceded. Moreover, as the hedge ratio $h^{G}$ goes down, the plan's total funding variation $J^{G}$ increases due to, at least, higher longevity risk.

\section{Managing Pension Longevity Risks with the Excess-Risk Hedging Strategy}

Although the ground-up hedging strategy in the "Managing Pension Longevity Risks with the Ground-Up Hedging Strategy" section reduces longevity risk, it has two major problems. First, it provides a protection that the plan may not need. The plan can predict its future payments to some extent and it is only uncertain about the amount exceeding its expectation. The cost of hedging is usually proportional to the amount of coverage. As such, the ground-up strategy is expensive. In addition, this strategy is capital intensive. It requires a large up-front premium, which the plan may not afford. The first longevity bond, the EIB bond issued in November 2004, is an example of the ground-up hedging strategy. It is a 25-year bond that provides a protection equal to the amount of a fixed annuity, $£ 50$ million, multiplied by the percentage of the reference population still alive at each anniversary. The coverage of this bond is illustrated as the solid filled bars in Figure 3.

The EIB bond offered a hedge to pension plans but the EIB did not sell. The ground-up protection structure, at least partially, explains its failure (Lin and Cox, 2008). A more attractive structure is the one that only covers the annuity payment that exceeds a certain strike level. The modified EIB bond we suggest is shown in Figure 4 . The unfilled area of each bar in Figure 4 represents the risk retained by the plan. The plan only cedes the longevity risk above the strike levels, which are represented as the solid filled bars. This illustrates the second strategy we examine in this section: the excess-risk hedging strategy. 


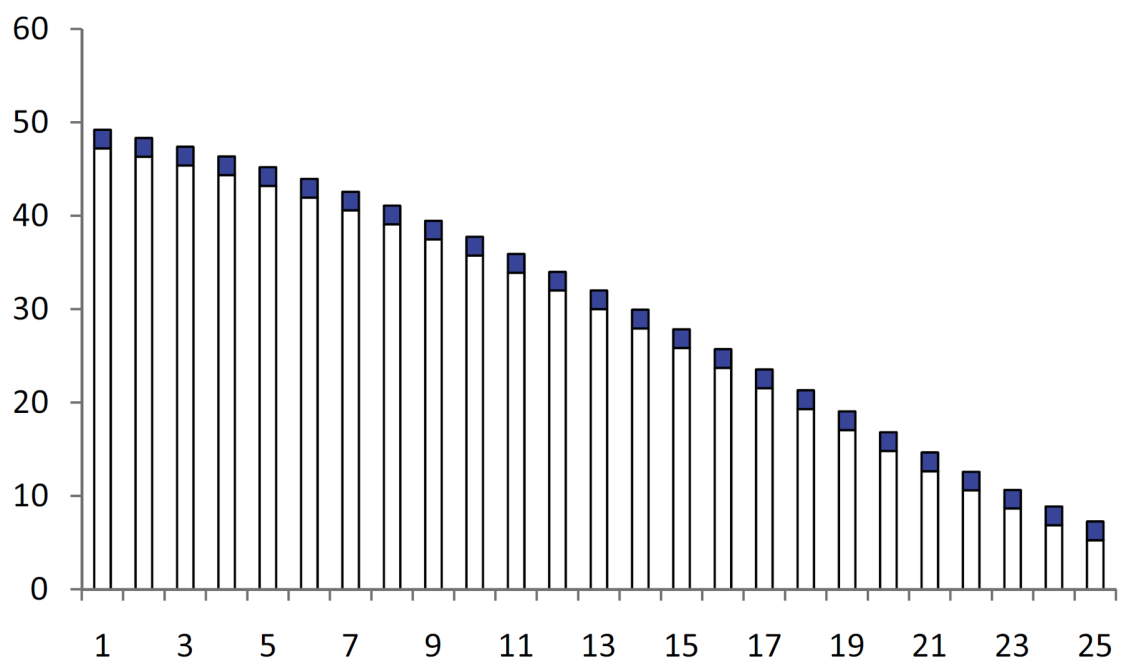

Figure 4. Coverage of the Modified EIB Longevity Bond Using the Excess-Risk Hedging Strategy. The solid filled bars show the protection provided by the excess-risk hedging strategy each year (millions in pounds) and time in years is on the horizontal axis.

With the excess-risk strategy, the plan needs to determine a threshold level for each of the years $T+1, T+2, \ldots$ above which to transfer a proportion $h^{E}$ of risk. Recall that the conditional expected s-year survival rate, ${ }_{s} \hat{p}_{x, T}$, for age $x$ at retirement $T$ is defined as,

$$
{ }_{s} \hat{p}_{x, T}=\mathrm{E}\left[{ }_{s} \tilde{p}_{x, T} \mid \tilde{p}_{x, T}, \tilde{p}_{x+1, T+1}, \ldots, \tilde{p}_{x+s-1, T+s-1}\right]
$$

which is random at time 0 . Suppose at time 0 , the plan transfers the risk that exceeds the plan's expectation, ${ }_{s} \bar{p}_{x, T}=\mathrm{E}\left[\hat{p}_{x, T}\right]$, after the plan participants reach the retirement age $x$ at time $T$,

$$
\max \left[B_{s} \hat{p}_{x, T}-B_{s} \bar{p}_{x, T}, 0\right] \quad s=1,2, \ldots,
$$

which can be viewed as a set of European call options written at time 0 and exercised at $T+1, T+2, \ldots$. In this example, the strike price equals the expected survival benefit, $B_{s} \bar{p}_{x, T} s=1,2, \ldots$ Of course, the plan can set a different threshold given its risk tolerance, for example, one or two standard deviations above the mean $B_{s} \bar{p}_{x, T^{\prime}} s=1,2, \ldots$ In the "Optimization with a Different Strike Level" section, we investigate how a change in the strike level will change the optimal hedging strategies. Because the excess-risk strategy only cedes the high-end risk, in general, it has a much lower capital requirement for the protection than the ground-up strategy. 
If the plan hedges a proportion $h^{E}$ of (42), it needs to pay a price equal to

$$
H P^{E}=\frac{h^{E}\left(1+\delta^{E}\right) E\left[\sum_{s=1}^{\infty} v^{s} \max \left[B_{s} \hat{p}_{x, T}-B_{s} \bar{p}_{x, T^{\prime}} 0\right]\right]}{(1+\rho)^{T}}
$$

where $\delta^{E}$ is the hedge cost per dollar hedged in the excess-risk hedging strategy and

$$
\mathrm{E}\left[\sum_{s=1}^{\infty} v^{s} \max \left[B_{s} \hat{p}_{x, T}-B_{s} \bar{p}_{x, T^{\prime}} 0\right]\right]
$$

is the present value of expected payments from the longevity risk taker at time $T$. As such, the plan's liability at the end of period $t$ becomes

$$
\begin{aligned}
& P B O_{t}^{E} \\
& = \begin{cases}\frac{B a(x(T))-B h^{E} \sum_{s=1}^{\infty} v^{s} \max \left[0,{ }_{s} \hat{p}_{x, T}-s_{s} \bar{p}_{x, T}\right]}{(1+\rho)^{T-t}} & t=1,2, \ldots, T \\
B a(y(t))-B h^{E} \sum_{s=t-T+1}^{\infty} v^{s-(t-T)} \max \left[0,{ }_{s} \hat{p}_{x, T}-{ }_{s} \bar{p}_{x, T}\right] & t=T+1, T+2, \ldots\end{cases}
\end{aligned}
$$

After the plan buys the excess-risk longevity hedge, the fund $M^{E}$ it can invest in the capital market at $t=0$ is

$$
M^{E}=M-H P^{E}
$$

The excess-risk hedging strategy should satisfy the following balance equation:

$$
\sum_{i=1}^{n} A_{i, t}^{E}= \begin{cases}P A_{t}^{E}+C^{E}+k \cdot U L_{t}^{E} & t=1,2, \ldots, T \\ P A_{t}^{E}+k \cdot U L_{t}^{E}-B \cdot t-T \hat{p}_{x, T} & \\ +B h^{E} \max \left[0, t-T \hat{p}_{x, T}-t-T \bar{p}_{x, T}\right] & t=T+1, T+2, \ldots\end{cases}
$$

In (44), the underfunding liability in the excess-risk strategy equals

$$
U L_{t}^{E}= \begin{cases}P B O_{t}^{E}-P A_{t}^{E}-C^{E} & t=1,2, \ldots, T \\ P B O_{t}^{E}-P A_{t}^{E}+B \cdot t-T \hat{p}_{x, T} & \\ \quad-B h^{E} \max \left[0, t-T \hat{p}_{x, T}-t-T \bar{p}_{x, T}\right] & t=T+1, T+2, \ldots\end{cases}
$$

where $P A_{t}^{E}$ is the value of pension assets at time $t$ before the plan makes contributions and pays survival benefits at time $t$. 
From (44) and (45), the total fund available for investment at time $t \leq T, \sum_{i=1}^{n} A_{i, t}^{E}$ can be written as

$$
\sum_{i=1}^{n} A_{i, t}^{E}=(1-k) \sum_{i=1}^{n} A_{i, t-1}^{E}\left(1+r_{i, t}\right)+(1-k) C^{E}+k \cdot P B O_{t}^{E}
$$

When $t>T, \sum_{i=1}^{n} A_{i, t}^{E}$ is calculated as:

$$
\begin{aligned}
\sum_{i=1}^{n} A_{i, t}^{E}= & (1-k) \sum_{i=1}^{n} A_{i, t-1}^{E}\left(1+r_{i, t}\right)-(1-k) B \cdot{ }_{t-T} \hat{p}_{x, T} \\
& +(1-k) B h^{E} \max \left[0, t-T \hat{p}_{x, T}-t-T \bar{p}_{x, T}\right]+k \cdot P B O_{t}^{E}
\end{aligned}
$$

Therefore, the value of asset $i$ at time $t$ given the weight $w_{i}^{E}$ is

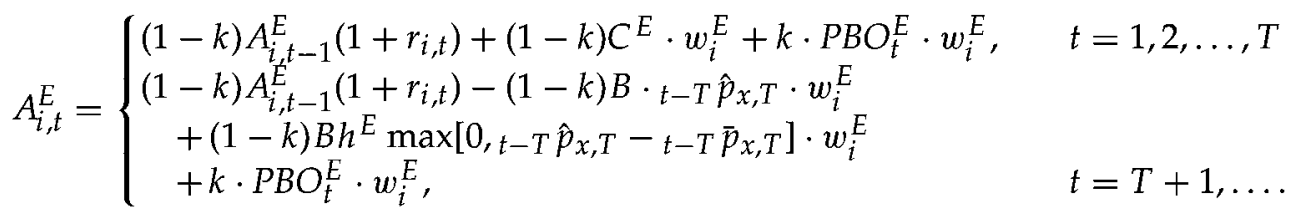

When $t=0, A_{i, 0}^{E}=w_{i} M^{E}$ for $i=1,2, \ldots, n$.

The excess-risk strategy has a total pension cost $T P C^{E}$ as follows:

$$
\begin{aligned}
\operatorname{TPC}^{E}= & \frac{h^{E} \delta^{E} \mathrm{E}\left[\sum_{s=1}^{\infty} v^{s} \max \left[B_{s} \hat{p}_{x, T}-B_{s} \bar{p}_{x, T}, 0\right]\right]}{(1+\rho)^{T}}+\sum_{t=1}^{T} \frac{C^{E}}{(1+\rho)^{t}} \\
& +\sum_{t=1}^{\infty} \frac{S C_{t}^{E}\left(1+\psi_{1}\right)-W_{t}^{E}\left(1-\psi_{2}\right)}{(1+\rho)^{t}}
\end{aligned}
$$

where $h^{E} \delta^{E} \mathrm{E}\left[\sum_{s=1}^{\infty} v^{s} \max \left[B_{s} \hat{p}_{x, T}-B_{s} \bar{p}_{x, T^{\prime}} 0\right]\right] /(1+\rho)^{T}$ is the total hedge cost. Recall that $T P C^{G}$ in (40) is the total pension cost of the ground-up hedging strategy. Both TPC ${ }^{G}$ and $T P C^{E}$ have a hedge cost component. However, the hedge cost components of these two strategies are not equal due to different hedging structures and possibly different unit hedge $\operatorname{costs}\left(\delta^{G}\right.$ vs. $\left.\delta^{E}\right)$. This can lead to very different optimal hedging solutions for these two strategies, which we will discuss later. 


\section{How to Manage Longevity Risks With the Excess-Risk Hedging Strategy?}

The optimal excess-risk hedging strategy is to solve the following optimization problem:

$$
\begin{aligned}
& \underset{w^{E}, C^{E}, h^{E}}{\operatorname{Minimize}} \quad \mathrm{E}\left[\sum_{t=1}^{\infty}\left(\frac{U L_{t}^{E}}{(\mathbf{1}+\rho)^{t}}\right)^{2}\right] \\
& \text { subject to } \quad E\left(T U L^{E}\right)=0 \\
& E\left(T P C^{E}\right)=\zeta \\
& \mathrm{CVaR}_{\alpha}\left(T U L^{E}\right) \leq \tau \\
& \frac{h^{E}\left(1+\delta^{E}\right) \mathrm{E}\left[\sum_{s=1}^{\infty} v^{s} \max \left[B_{s} \hat{p}_{x, T}-B_{s} \bar{p}_{x, T}, 0\right]\right]}{(1+\rho)^{T}} \leq M \\
& 0 \leq h^{E} \leq 1 \\
& 0 \leq w_{i}^{E} \leq 0, \quad i=1,2, \ldots, n \\
& \sum_{i=1}^{n} w_{i}^{E}=1 \\
& C^{E} \geq 0
\end{aligned}
$$

where $T U L^{E}=\sum_{t=1}^{\infty} \frac{U L_{t}^{E}}{(1+\rho)^{t}}$. The constraint

$$
\frac{h^{E}\left(1+\delta^{E}\right) \mathrm{E}\left[\sum_{s=1}^{\infty} v^{s} \max \left[B_{s} \hat{p}_{x, T}-B_{s} \bar{p}_{x, T}, 0\right]\right]}{(1+\rho)^{T}} \leq M
$$

ensures the premium does not exceed the pension fund at $t=0$.

\section{Example}

Continue the example as in the section mentioned initially. This time the plan adopts the excess-risk hedging strategy with the strike level $B_{s} \bar{p}_{x, T}, s=1,2, \ldots$ and $T=20$. It solves problem (50) to obtain the optimal normal contributionCE, the asset allocations $w_{i}^{E}(i=1$, $2,3)$, and hedge ratio $h^{E}$ that will minimize the total funding variation,

$$
J^{E}=\mathrm{E}\left[\sum_{t=1}^{\infty}\left(\frac{U L_{t}^{E}}{(1+\rho)^{t}}\right)^{2}\right]
$$

subject to $\mathrm{E}\left(T U L^{E}\right)=0, \mathrm{E}\left(T P C^{E}\right)=\zeta=15.01$, and $C V a R_{95 \%}\left(T U L^{E}\right) \leq \tau=59.63$.

Table 5 summarizes the results with different unit hedge costs $\delta^{E}$. As long as $\delta^{E}$ is not higher than 0.10, the plan will transfer longevity risk that exceeds the strike level with 
Table 5. Optimal Excess-Risk Hedging Strategies With Different Assumptions on Hedge Cost Parameter $\delta^{E}$ Given $\zeta=15.01, \tau=59.63, g=-0.20$, and the Strike Level $B_{s} \bar{p}_{x, T}, s=1,2, \ldots$ and $T=20$

\begin{tabular}{lccccccc}
\hline$\delta^{E}$ & $C^{E}$ & $w_{1}^{E}$ & $w_{2}^{E}$ & $w_{3}^{E}$ & $h^{E}$ & $\mathrm{CVaR}_{95 \%}\left(\mathrm{TUL}^{E}\right)$ & $J^{E}$ \\
\hline 0.000 & 1.07 & $17.07 \%$ & $69.14 \%$ & $13.80 \%$ & $100 \%$ & 56.08 & 931.62 \\
0.050 & 1.07 & $16.93 \%$ & $69.69 \%$ & $13.38 \%$ & $100 \%$ & 56.19 & 934.03 \\
0.075 & 1.07 & $17.03 \%$ & $69.67 \%$ & $13.30 \%$ & $79 \%$ & 56.78 & 935.19 \\
0.090 & 1.07 & $16.91 \%$ & $70.18 \%$ & $12.90 \%$ & $30 \%$ & 58.52 & 935.58 \\
0.095 & 1.07 & $17.11 \%$ & $69.79 \%$ & $13.10 \%$ & $15 \%$ & 59.02 & 935.62 \\
0.100 & 1.07 & $17.13 \%$ & $69.82 \%$ & $13.06 \%$ & $0 \%$ & 59.63 & 935.63 \\
\hline
\end{tabular}

$h^{E}>0$. In these cases, the total funding variations $J^{E}$ are all lower than the case without hedging longevity risk. However, the hedging will not do anything good when $\delta^{E} \geq 0.10$ so the plan chooses to retain all risks $\left(h^{E}=0\right.$ percent).

The hedge ratios $h^{E}$ in Table 5 are much higher than $h^{G}$ for the ground-up hedging in Table 4, which creates an apparent contrast between the excess-risk strategy and the groundup strategy. This can be explained by the more attractive structure and the lower capital requirement of the excess-risk strategy. The excess risk strategy only covers the payment above the strike level. However, the ground-up strategy covers the entire risk, including the payment the plan can predict reasonably. As such, the ground-up strategy requires a higher price that reflects the higher future payments from the hedge provider. This means the plan has to give up a large proportion of the initial fund $M$ and forgo possibly higher returns from the capital market. In this case the plan decides to hedge less. Moreover, the hedge cost increases with the amount of coverage. The unneeded coverage provided by the ground-up strategy increases the hedge cost. This further discourages the plan from hedging with the ground-up strategy. In contrast, the excess-risk strategy focuses on the protection the plan really needs. In our example, as long as the unit hedge cost is not too high $\left(\delta^{E} \leq 0.05\right)$, the plan will hedge all of the excess longevity risk.

One must use caution when comparing the total funding variation $J^{G}$ in Table 4 with $J^{E}$ in Table 5. One might find it striking that many values of $J E$ in Table 5 are higher than those of $J^{G}$ in Table 4 and then might conclude that the excess-risk strategy retains a higher extreme longevity risk. This may not be true because this belief does not recognize that the total funding variation reflects not only longevity risk, but also investment risk. Actually, the higher variation $J^{E}$ in the excess-risk strategy arises from the higher amount available for asset investments (i.e., $M^{E}>M^{G}$ ). In our example, the expected annuity payment $B \bar{a}(x(T))$ equals $\$ 110.13$ million and the expected excess-risk payment is

$$
\mathrm{E}\left[\sum_{s=1}^{\infty} v^{s} \max \left[B_{s} \hat{p}_{x, T}-B_{s} \bar{p}_{x, T}, 0\right]\right]=\$ 1.34 \text { million }
$$


Assuming $\delta^{G}=\delta^{E}=0$, the price of the ground-up hedging strategy paid to the risk taker at $t=0$ is

$$
\begin{aligned}
H P^{G} & =\frac{h^{G}\left(1+\delta^{G}\right) B \bar{a}(x(T))}{(1+\rho)^{T}} \\
& =\frac{21 \% \times 1 \times 110.13}{1.08^{20}}=\$ 4.96 \text { million, }
\end{aligned}
$$

while the price of the excess-risk strategy is only

$$
\begin{aligned}
H P^{E} & =\frac{h^{E}\left(1+\delta^{E}\right) \mathrm{E}\left[\sum_{s=1}^{\infty} v^{s} \max \left[B_{s} \hat{p}_{x, T}-B_{s} \bar{p}_{x, T}, 0\right]\right]}{(1+\rho)^{T}} \\
& =\frac{100 \% \times 1 \times 1.34}{1.08^{20}}=\$ 0.29 \text { million. }
\end{aligned}
$$

This implies that the initial fund available for asset investment in the ground-up strategy is

$$
P A_{0}^{G}=M^{G}=5-4.96=\$ 0.04 \text { million, }
$$

which is much lower than that in the excess-risk strategy

$$
P A_{0}^{E}=M^{E}=5-0.29=\$ 4.71 \text { million. }
$$

Since the risky assets' volatility, in general, is much higher than that of longevity risk, we observe a higher funding variation of the excess-risk strategy. Nevertheless, the excess-risk strategy has a much lower high-end longevity risk than the ground-up strategy as $h^{E}>h^{G}$ for all cases when $\delta E=\delta G<0.10$ as illustrated in this example.

Discussion of Asset Allocations With and Without Hedging. In our article, we follow a common assumption in the pension literature that the stochastic processes for assets and mortality are independent. ${ }^{9}$ With this setting, the main driver of the interaction between investment risk and longevity risk is the hedge price paid to the longevity risk taker. After a plan sets its target expected total pension cost and downside risk level, the hedge price the plan pays for the ceded risk determines the amount available for asset investments that in turn affects asset allocation. In our example, to achieve the lowest funding variation without hedging, on average, the plan should invest 17.13 percent of the funds in the S\&P 500 index, 69.82 percent in the Merrill Lynch corporate bond index, and the remaining funds should be invested in the 3-month T-bill with 13.06 percent as shown earlier in Table 2 and reproduced for comparison in Table 6.

9. This is a common assumption but it may not always be the case. We leave this question for future research. 
Table 6. Asset Allocation Comparison Given $\delta^{G}=\delta^{E}=0, \zeta=15.01, \tau=59.63, g=-0.20$ for All Cases, and the Strike Level $B_{s} \bar{p}_{x, T}, s=1,2, \ldots$ and $T=20$ for the Excess-Risk Strategy

\begin{tabular}{lccccc}
\hline & Hedge Price & $w_{1}$ & $w_{2}$ & $w_{3}$ & Hedge Ratio \\
\hline No hedge & 0.00 & $17.13 \%$ & $69.82 \%$ & $13.06 \%$ & $0 \%$ \\
Ground-up hedge & 4.96 & $19.37 \%$ & $77.87 \%$ & $2.76 \%$ & $21 \%$ \\
Excess-risk hedge & 0.29 & $17.07 \%$ & $69.14 \%$ & $13.80 \%$ & $100 \%$ \\
\hline
\end{tabular}

Table 7. Optimal Excess-Risk Hedging Strategies With Different Assumptions on Hedge Cost Parameter $\delta^{E}$ Given $\zeta=15.01, \tau=59.63, g=-0.20$, and the Strike Level $B_{s} \bar{p}_{x, T}+\sigma_{B_{s}} \hat{p}_{x, T}, s=1,2, \ldots$ and $T=20$

\begin{tabular}{lccccccc}
\hline$\delta^{E}$ & $C^{E}$ & $w_{1}^{E}$ & $w_{2}^{E}$ & $w_{3}^{E}$ & $h^{E}$ & $\mathrm{CVaR}_{95 \%}\left(\mathrm{TUL}^{E}\right)$ & $J^{E}$ \\
\hline 0.000 & 1.07 & $17.14 \%$ & $69.62 \%$ & $13.24 \%$ & $100 \%$ & 58.49 & 934.52 \\
0.050 & 1.07 & $17.12 \%$ & $69.72 \%$ & $13.16 \%$ & $100 \%$ & 58.49 & 935.03 \\
0.100 & 1.07 & $17.05 \%$ & $69.94 \%$ & $13.01 \%$ & $91 \%$ & 58.60 & 935.52 \\
0.110 & 1.07 & $17.20 \%$ & $69.62 \%$ & $13.18 \%$ & $51 \%$ & 59.03 & 935.60 \\
0.120 & 1.07 & $17.07 \%$ & $69.93 \%$ & $13.00 \%$ & $24 \%$ & 59.37 & 935.62 \\
0.125 & 1.07 & $17.13 \%$ & $69.82 \%$ & $13.06 \%$ & $0 \%$ & 59.63 & 935.63 \\
\hline
\end{tabular}

If the hedge price is high and the available fund for investment is low, the difference in asset allocation between the no-hedge case and the hedge case will be large. For example, given $\delta^{G}=\delta^{E}=0$, Table 6 shows the hedge price for the ground-up strategy $\left(H P^{G}=\$ 4.96\right.$ million) is much higher than that of the excess-risk strategy $\left(H P^{E}=\$ 0.29\right.$ million). As such, we observe a much more significant change in asset allocation for the ground-up strategy than for the excess-risk strategy, both compared to the no-hedge case. The ground-up strategy invests almost all of its funds, 97.24 percent $(=19.37+77.87$ percent $)$ in risky assets, notably higher than 86.94 percent without hedge and 86.20 percent with the excessrisk strategy.

\section{Optimization With a Different Strike Level}

We next turn our attention to the optimal solutions with a different strike level. In the earlier example we set the strike level at the expected benefit payment $B_{s} \bar{p}_{x, T}, s=1,2, \ldots$ and $T=$ 20. The plan may want to set a higher strike level such as one standard deviation above the expected payment, that is, $B_{s} \bar{p}_{x, T}+\sigma_{B_{s}} \hat{p}_{x, T}$ where $\sigma_{B_{s}} \hat{x}_{x, T}$ is the standard deviation of $B_{s} \hat{p}_{x, T}$.

In this case, the optimization results are shown in Table 7. Table 7 presents a pattern similar to that in Table 5: the plan transfers the entire longevity risk ( $h=100$ percent) as long as the unit hedge $\operatorname{cost} \delta^{E}$ is not too high. As the strike level goes up, the maximum allowed $\delta^{E}$ to ensure a positive hedge ratio increases. In our example, the maximum allowed $\delta^{E}$ increases from 0.095 to 0.12 , a 26 percent rise, when the strike level increases from $B_{s} \bar{p}_{x, T}$ to $B_{s} \bar{p}_{x, T}$ $+\sigma_{B_{s}} \hat{p}_{x, T}, s=1,2, \ldots$ and $T=20$. The fact that the maximum acceptable unit hedge cost $\delta^{E}$ 
increases with the strike level reflects the risk aversion of pension plans toward catastrophic longevity risk as the high-end risk is more difficult to predict and if it occurs, it will lead to more serious financial consequences. Thus, the risk averse plan chooses to hedge more at a higher strike level even if the unit hedge $\operatorname{cost} \delta^{E}$ increases (but up to a limit).

\section{Implications for Longevity Securitization}

Packaging longevity risk through securitization was first advocated by Blake and Burrows (2001) to help pension plans transfer longevity risk. Since then, it has been widely discussed by both academics and practitioners (Lin and Cox, 2005, 2008; Cox, Lin, and Wang, 2006; Blake et al., 2006; Cairns, Blake, and Dowd, 2006; Cox and Lin, 2007; Sherris and Wills, 2008; Cox, Lin, and Petersen, 2010; Wills and Sherris, 2010; Milidonis, Lin, and Cox, 2011; Cox et al., Forthcoming; Lin, Liu, and Yu, Forthcoming). However, many of the possible capital market solutions for longevity risk remain theoretical. Before 2010, the market for longevity securities did not really take off, although there were limited experiments with products assuming longevity risk (Standard \& Poor's, 2010). Since the past a couple of years, investment banks have been actively exploring this space. Our optimization results provide important insights for longevity securitization that may draw pension plans to this market and allow transaction activity to grow.

First, the market should design appealing longevity securities that can attract pension plans. As our results indicate, the pension plans are inclined to transferring more longevity risk with the excess-risk hedging strategy since it is less capital intensive and more cost effective. In July 2008, Canada Life traded a survivor swap with a group of insurancelinked security investors. This is the first publicly known longevity security successfully executed. Although this deal has no pension plan involvement, it does provide support for the pension plans to pursue the excess-risk strategy. As we observe in the market, this strategy has gained momentum. Notably, six longevity swaps were completed in the United Kingdom in 2009 covering liabilities of approximately $£ 4.1$ billion (Brcic and Brisebois, 2010).

Second, longevity securities should not be too expensive. The EIB longevity bond in 2004 received much attention in the financial press because it was considered as the first longevity security. However, no pension funds and life insurance companies subscribed to the deal and it failed. Besides technical issues such as the design problems we discussed earlier, Thomsen and Andersen (2007) and Lin and Cox (2008) conclude that one of the major reasons why the EIB issue was withdrawn without being issued is because the pension industry found the price of coverage on longevity risk is too high. Our model indicates that the longevity hedge ratio is a decreasing function of unit hedge cost. If the hedge cost per dollar hedged $\left(\delta^{G}\right.$ or $\left.\delta^{E}\right)$ is too high, the plan will not transfer its longevity risk. In this sense, our model can be used to explain the failure of the EIB bond from the perspective of pension asset-liability optimization.

Our model can also be used to explain the reluctance of pension plans to use capital markets to hedge longevity risk. The current high transaction costs in the capital market discourage the plans from transferring longevity risk. This problem can be mitigated by standardizing longevity transactions. For example, we can promote consistent best market practices and publish tradable longevity indices. Such efforts will provide greater transparency 
and confidence for this market, and increase transaction activity. Standardization can also alleviate the problems related to investor education and barriers to entry because it helps investors to understand those complex longevity securities and promotes price convergence between buyers and sellers. The longevity market is expected to develop more standardization to allow a broader range of investors to enter the market. As pointed out by Manish Kapoor, "We'll see more efforts at standardization between transactions, and as that occurs, increased liquidity - albeit to a limited extent - and the ability to novate or exit structures. It will be interesting to see how the pricing changes as capital market participants other than insurers and reinsurers enter [longevity securitization markets]" (Standard \& Poor's, 2010). As liquidity increases, the cost of longevity securities will go down and we expect more pension plans to enter into these transactions.

\section{Conclusion}

This article proposes a model to identify the optimal contribution, asset allocation, and longevity risk hedging strategies that minimize total funding risk for a DB plan throughout the life of a single pension cohort. Given a target expected total pension cost, zero expected total unfunded liability, and a CVaR constraint on total unfunded liability, we minimize the plan's total funding variation across all years before and after retirement until the death of the last pension participant.

Then we investigate how sensitive the plan is to longevity risk given a downside risk tolerance. Populations all over the world have enjoyed increasing life expectancy in the last century. This trend is expected to continue in the future (KPMG LLP, 2008). It makes clear the need to study the impact of mortality improvement on the plan's asset-liability management. Given a level of 95 percent $\mathrm{CVaR}$ on total unfunded liability, we investigate how normal contribution, asset allocation, and total pension cost will change with the life expectancy of pensioners. Our results show that as pensioners live longer, the plan has to make a higher normal contribution, invest more in the low-risk asset, and pay a much higher expected total pension cost. This can cause a serious financing problem, in particular, for firms with capital constraints.

To mitigate the longevity effect, as another contribution of this article, we examine the plan's optimal longevity risk management decision and compare two longevity risk hedging strategies - the ground-up hedging strategy and the excess-risk hedging strategy. Our optimization results show that the longevity hedge ratio is negatively related to the unit hedge cost. The plan tends to hedge more with the excess-risk strategy due to its lower total hedge cost and more attractive structure. Our results also explain the failure of the 2004 EIB longevity bond and the emergence of longevity swaps in recent years: the EIB bond has a design similar to the ground-up strategy and the longevity swaps have a structure similar to the excess-risk strategy. ${ }^{10}$ As far as we know, this is the first article that incorporates longevity risk management into a pension plan's assetliability optimization problem.

We believe this article presents the starting point of a new way of thinking about pension longevity risk management in the optimization context. As such, it leaves some questions

10. A longevity swap can be flexible and tailor made, providing fixed-for-floating payments against a mortality index. 
unanswered and in turn opens lines for further research. First, notice that we only consider pension longevity risk management. This is based on the assumption of no hedge on pension assets.We would likely obtain richer results from a model in which the plan makes hedging decisions on both asset and liability risks. Second, we study the plan's optimization decision at one moment. It would be of interest to investigate a multiperiod decision model to adjust contribution and asset allocation in each period as that in Bogentoft, Romeijn, and Uryasev (2001). Further questions involve to what extent our results are affected by the assumption that the stochastic processes for assets and mortality rates are independent. This is a common assumption but it may not always be the case as shown in Lin, MacMinn, and Tzeng (2011). We leave these questions for future research.

\section{References}

Black, F., 1980, The Tax Consequences of Long-Run Pension Policy, Financial Analysts Journal, 36: 21-28.

Black, F., 1989, Should You Use Stocks to Hedge Your Pension Liability, Financial Analysts Journal, 45: 10-12.

Blake, D., and W. Burrows, 2001, Survivor Bonds: Helping to Hedge Mortality Risk, Journal of Risk and Insurance, 68: 339-348.

Blake, D., A. J. G. Cairns, K. Dowd, and R. MacMinn, 2006, Longevity Bonds: Financial Engineering, Valuation, and Hedging, Journal of Risk and Insurance, 73: 647-672.

Bodie, Z., 1991, Shortfall Risk and Pension Fund Asset Management, Financial Analysts Journal, 47: 57-61.

Bogentoft, E., H. E. Romeijn, and S. Uryasev, 2001, Asset/Liability Management for Pension Funds Using CVaR Constraints, Journal of Risk Finance, 3: 57-71.

Brcic, J., and C. Brisebois, 2010, An Age-Old Story. http://www.benefitscanada.com (April 2010)

Cairns, A. J. G., D. Blake, and K. Dowd, 2006, Pricing Death: Frameworks for the Valuation and Securitization of Mortality Risk, ASTIN Bulletin, 36: 79-120.

Chang, S. C., L. Y. Tzeng, and J. C. Miao, 2003, Pension Funding Incorporating Downside Risks, Insurance: Mathematics and Economics, 32: 217-228.

Colombo, L., and S. Haberman, 2005, Optimal Contributions in a Defined Benefit Pension Scheme With Stochastic New Entrants, Insurance: Mathematics and Economics, 37: 335354.

Cox, S. H., and Y. Lin, 2007, Natural Hedging of Life and Annuity Mortality Risks, North American Actuarial Journal, 11: 1-15.

Cox, S. H., Y. Lin, and H. Petersen, 2010, Mortality Risk Modeling: Applications to Insurance Securitization, Insurance: Mathematics and Economics, 46: 242-253.

Cox, S. H., Y. Lin, R. Tian, and L. F. Zuluaga, Forthcoming, Mortality Portfolio Risk Management, Journal of Risk and Insurance.

Cox, S. H., Y. Lin, and S. Wang, 2006, Multivariate Exponential Tilting and Pricing Implications for Mortality Securitization, Journal of Risk and Insurance 73: 719-736. 
Delong, Ł., R. Gerrard, and S. Haberman, 2008, Mean-Variance Optimization Problems for an Accumulation Phase in a Defined Benefit Plan, Insurance: Mathematics and Economics, 42: 107-118.

Franzoni, F., and J. M. Marin, 2006, Pension Plan Funding and Stock Market Efficiency, Journal of Finance, 61: 921-956.

Gold, J., and N. Hudson, 2003, Creating Value in Pension Plans (or, Gentlemen Prefer Bonds), Journal of Applied Corporate Finance, 15: 51-57.

Haberman, S., 1997, Stochastic Investment Returns and Contribution Rate Risk in a Defined Benefit Pension Scheme, Insurance: Mathematics and Economics, 19: 127-139.

Haberman, S., Z. Butt, and C. Megaloudi, 2000, Contribution and Solvency Risk in a Defined Benefit Pension Scheme, Insurance: Mathematics and Economics, 27: 237-259.

Haberman, S., and J. Sung, 1994, Dynamic Approaches to Pension Funding, Insurance:Mathematics and Economics, 15: 151-162.

Haberman, S., and J.-H. Sung, 2005, Optimal Pension Funding Dynamics Over Infinite Control Horizon When Stochastic Rates of Return Are Stationary, Insurance:Mathematics and Economics, 36: 103-116.

Josa-Fombellida, R., and J. P. Rincón-Zapatero, 2001, Minimization of Risks in Pension Funding by Means of Contribution and Portfolio Selection, Insurance: Mathematics and Economics, 29: 35-45.

Josa-Fombellida, R., and J. P. Rinc'on-Zapatero, 2004, Optimal Risk Management in Defined Benefit Stochastic Pension Funds, Insurance: Mathematics and Economics, 34: 489-503.

Kelly, D., 2012, Prudential Signs Pension Transfer Agreement With General Motors Co. http://news.prudential.com (June 2012).

Kouwenberg, R., 2001, Scenario Generation and Stochastic Programming Models for Asset Liability Management, European Journal of Operational Research, 34: 279-292.

KPMG LLP, 2008, Managing Longevity Risk. http://www.kpmgmandamonthly.com (October 2010).

Lee, E., 1986, An Introduction to Pension Schemes (London, UK: Institute of Actuaries and Faculty of Actuaries).

Lee, R. D., and L. Carter, 1992, Modelling and Forecasting the Time Series of US Mortality, Journal of the American Statistical Association, 87: 659-671.

Lin, T., R. MacMinn, and L. Y. Tzeng, 2011, Population and Asset Pricing, Working Paper, National Chung Cheng University, Illinois State University, and National Taiwan University.

Lin, Y., and S. H. Cox, 2005, Securitization of Mortality Risks in Life Annuities. Journal of Risk and Insurance 72: 227-252.

Lin, Y., and S. H. Cox, 2008, Securitization of Catastrophe Mortality Risks, Insurance:Mathematics and Economics, 42: 628-637.

Lin, Y., S. Liu, and J. Yu, Forthcoming, Pricing Mortality Securities With Correlated Mortality Indices, Journal of Risk and Insurance.

Lucas, D. J., and S. P. Zeldes, 2009, How Should Public Pension Plans Invest? American Economic Review, 99: 527-532. 
Maurer, R., O. S. Mitchell, and R. Rogalla, 2009, Managing Contribution and Capital Market Risk in a Funded Public Defined Benefit Plan: Impact of Cvar Cost Constraints, Insurance: Mathematics and Economics, 45: 25-34.

Milidonis, A., Y. Lin, and S. H. Cox, 2011, Mortality Regimes and Pricing, North American Actuarial Journal, 15: 266-289.

Sherris, M., and S. Wills, 2008, Financial Innovation and the Hedging of Longevity Risk, Asia-Pacific Journal of Risk and Insurance, 3: 52-64.

Standard \& Poor's, 2010, U.S. Structured Credit Roundtable: Longevity Securitization Is Poised for Growth as New Investors Step Into the Market. http://www. standardandpoors.com (see the news release for December 22, 2010).

Thomsen, J., and J. V. Andersen, 2007, Longevity Bonds: A Financial Market Instrument to Managec Longevity Risk; http://www.pensionsinstitute.org (Monetary Review).

Wills, S., and M. Sherris, 2010, Securitization, Structuring and Pricing of Longevity Risk, Insurance: Mathematics and Economics, 46: 173-185. 